\title{
Obesity and the Labor Market: A Fresh Look at the Weight Penalty
}

\author{
Marco Caliendo* \\ Markus Gehrsitz ${ }^{\dagger}$ \\ Re-Submission to: Economics and Human Biology
}

July 21, 2016

\begin{abstract}
This paper applies semiparametric regression models to shed light on the relationship between body weight and labor market outcomes in Germany. We find conclusive evidence that these relationships are poorly described by linear or quadratic OLS specifications. Women's wages and employment probabilities do not follow a linear relationship and are highest at a body weight far below the clinical threshold of obesity. This indicates that looks, rather than health, is the driving force behind the adverse labor market outcomes to which overweight women are subject. Further support is lent to this notion by the fact that wage penalties for overweight and obese women are only observable in white-collar occupations. On the other hand, bigger appears to be better in the case of men, for whom employment prospects increase with weight, albeit with diminishing returns. However, underweight men in blue-collar jobs earn lower wages because they lack the muscular strength required in such occupations.
\end{abstract}

Keywords: Obesity, Wages, Employment, Semiparametric Regression, Gender Differences

JEL codes: J31, J71, C14

\footnotetext{
${ }^{*}$ University of Potsdam, IZA Bonn, DIW Berlin, IAB Nuremberg, e-mail: caliendo@uni-potsdam.de.

${ }^{\dagger}$ The City University of New York, e-mail: mgehrsitz@gradcenter.cuny.edu. Corresponding address: The City University of New York, Graduate Center, 365 5th Avenue, New York, NY, 10016, USA.

We thank the co-editor-in-chief, Inas R. Kelly, and three anonymous reviewers for valuable comments and suggestions. Further, we thank Karina Doorley, Anne Gielen, Michael Grossman, David Jaeger, Wim Vijverberg and the participants of the CUNY dissertation seminar for helpful comments and discussions. A supplementary appendix with additional material is available on request from the authors and online.
} 


\section{Introduction}

Obesity is a major public health issue that has caused billions of dollars in medical expenditures and contributes to hundreds of thousands of deaths every year (Mokdad, Serdula, Dietz, Bowman, Marks, and Koplan, 1999). The obesity epidemic has also spilled over into the labor market. A negative association between body weight and wages is well established in the labor economics literature. It has been observed in the United States (Averett and Korenman, 1996; Cawley, 2004; Conley and Glauber, 2006, among others), as well as in European countries such as Denmark (Greve, 2008), England (Morris, 2006), Finland (Johansson, Backerman, Kiiskinen, and Helivaara, 2009), France (Paraponaris, Saliba, and Ventelou, 2005), Germany (Cawley, Grabka, and Dean, 2005), Sweden (Lundborg, Nystedt, and Rooth, 2014), and even in Taiwan (Tao, 2008).

Higher weight is not only associated with drawbacks for those in employment, but also for those searching for a job. Chubby job seekers have considerably lower chances of initially finding a job than their slimmer, equally qualified peers (Lindeboom, Lundborg, and van der Klaauw, 2010; Garcia and Quintana-Domeque, 2006, among others) and certain jobs are not even open to overweight applicants (Cawley and Maclean, 2012). Obese unemployed are forced to spend more time on welfare (Cawley and Danziger, 2005). In addition, being overweight has adverse effects on those who already face obstacles in the job market. For instance, heavy women tend to be more prone to adverse labor market outcomes than overweight men (Mocan and Tekin, 2011). There is also evidence that they have less success in their transition back to employment, despite putting in more effort and having lower reservation wages (Caliendo and Lee, 2013).

While previous research has consistently uncovered a negative relationship between body weight and labor market outcomes, non-linearities in the relationship and heterogeneous effects remain under-explored. Most studies merely apply linear or dummy variable regressions of wages on body weight. Recent studies by Gregory and Ruhm (2011) for the US and a European cross-country analysis by Hildebrand and Van Kerm (2010) indicate that these functional forms might fail to capture important details in the association between wages and body weight; moreover, few studies account for heterogeneity across different occupational categories. Based on data from the German Socio-Economic Panel, our study fills these gaps in the literature. First, we apply a semiparametric model that allows for a flexible functional form. Second, we divide our sample into blue-collar and 
white-collar workers, and distinguish between occupations in which physical attractiveness is productivity-enhancing and those where it is not. To the best of our knowledge, we are also the first to apply a semiparametric model to gain insights on the relationship between employment and body weight.

Our results indicate looks-based discrimination against women in terms of lower wages, albeit only in white-collar jobs. Even women of normal weight are subject to wage penalties, and thus it might be misleading to refer to this effect as an "obesity penalty". Our analysis also suggests that what at first glance appears to be looks-based discrimination against underweight men more likely results from a lack of fitness and strength, which tend to be of particular importance in blue-collar jobs. Our results are robust to the inclusion of controls for muscle strength and also hold up when we further stratify our sample by job type and age. Altogether, we find a level of heterogeneity, which partly confirms the findings of previous studies, but also shows them in a different complexion.

We also find that the employment probability peaks for women way before the clinical threshold of obesity is reached. On the other hand, a parametric probit model would have suggested continuously declining employment probabilities in body weight. For men, we find that the propensity for employment peaks at a body weight that is actually quite close to the obesity threshold. While our semiparametric approach addresses functional form issues in an innovative way, it is no remedy for the endogeneity issues plaguing the literature. After all, obesity is not randomly assigned and likely to be correlated with omitted unobservables that also affect labor market outcomes. As a result our estimates do not have a causal interpretation, although they shed additional light on the relationship between obesity labor market outcomes.

The remainder of the paper is organized as follows. Section 2 describes the data used and presents first descriptive evidence on the outcomes of interest. In Section 3 we discuss our methodological approach before presenting the results in Section 4. Finally, Section 5 concludes and provides an outlook for further research. 


\section{Data and Descriptives}

\subsection{Estimation Sample}

For our analysis we use data from the German Socio-Economic Panel (SOEP) which is an annual representative household panel study that collects detailed information about the socio-economic circumstances of approximately 30,000 individuals across in Germany (see Wagner, Frick, and Schupp, 2007, for details). We focus on the waves 2002, 2004, 2006, and 2008 of the survey, during which information on both body weight and height was obtained from all participants. We pool data from different waves, but only use the most recent observation for each respondent. ${ }^{1}$ From this information, we construct each respondent's Body Mass Index (BMI) as the main explanatory variable of our study. BMI is the most commonly used measure of obesity (see Burkhauser and Cawley, 2008, for a discussion of the merits and demerits of using this measure). It is defined as an adult's weight in kilograms divided by the square of his or her height in meters. The World Health Organization (WHO) deems individuals with a BMI between 20 and 25 as having a healthy "normal" weight. Individuals with a BMI higher than 30 are classified as obese, while those with a BMI between 25 and 30 are rated as overweight (WHO, 2000). Obesity and, to a lesser degree, being overweight, is significantly associated with poor health and higher mortality in general (Allison, Fontaine, Manson, Stevens, and VanItallie, 1999), and diabetes, high cholesterol, and high blood pressure in particular (Mokdad, Ford, Bowman, Dietz, Bales, and Marks, 2003). Obesity is also one of the main causes for rising health care costs (Cawley and Meyerhoefer, 2012).

Height and weight are self-reported in the SOEP. There is a tendency to underreport weight and overreport height due to reasons of social desirability and age. For example, Strauss (1999) shows that adolescent girls tend to underreport their weight. This might slightly bias our results towards zero. Previous studies, e.g. Cawley (2004), tried to correct potential reporting error by applying a method developed by Bound, Brown, and Mathiowetz (2001), which relies on measured weight and height of participants of the National

\footnotetext{
${ }^{1}$ While panel attrition might be a concern in this context, there is little evidence for differential attrition with respect to either the main outcome or the main explanatory variable. A related concern is sample selectivity. For that reason, we re-run our analysis without selecting observations from the 2008 wave where possible and obtained virtually identical results. We also re-run our analysis by randomly selecting a wave for each individual in our sample, again the results were similar. The results of these robustness checks are available online in a supplementary appendix. For more information on attrition and re-participation rates (which are generally at around 90\%) in the SOEP see Kroh (2011).
} 
Health and Nutrition Examination Survey (NHANES III). We refrain from adjusting our BMI measure since we have no such benchmark study available for Germany, and the merits of this method are not beyond doubt (Han, Norton, and Stearns, 2009).

The dependent variable in our wage specification is the (log) hourly wage rate, which is constructed from the reported weekly earnings and hours of work. We also adjust wages from different waves for inflation. Respondents who claim to have hourly wages that exceed $€ 300$ or lie below $€ 2$ are not considered in our analysis. ${ }^{2}$ Naturally, we only observe wages for respondents who are in employment. Moreoever, we focus on the prime-age employment body and therefore exclude pensioners, military personnel, and respondents who are currently attending school or college, or undertake an apprenticeship or traineeship. We only include employees who work at least 20 hours per week in our wage regression. As indicated above, bodyweight might also affect a person's employment prospects and thus the ability to earn positive wages in the first place. Therefore, we also run a regression of employment on bodyweight. Our dependent variable is a dummy that adopts a value of 1 if a person is employed or self-employed, and works at least 1 hour per week, and zero otherwise.

\section{INSERT TABLE 1 ABOUT HERE}

Table 1 describes the construction of our estimation sample in more detail. In order to avoid data issues pertaining to retirement and schooling, we limit our analysis to persons between the ages of 20 and 60. We drop individuals with disabilities and for whom the weight/height information is imputed, missing or implausible. ${ }^{3}$ We also drop individuals who have missing values in key socio-economic control variables. Our final estimation sample comprises 9,621 men and 10,022 women.

\subsection{Descriptive Statistics}

The average BMI in our sample is 24.58 for women and 26.23 for men (see Table 2). Almost 60 percent of the men in our sample are either overweight or obese, compared to a little more than one-third of women. From Figure 1 it is apparent that the number of

\footnotetext{
${ }^{2}$ This restriction leads us to drop 173 observations. We test for the effect of outliers through a $90 \%$ winsorization which does not affect our results. We thank an anonymous referee for suggesting this robustness test, detailed results of this robustness check are available from the authors upon request.

${ }^{3}$ In particular, we drop 18 observations which report weight in excess of $250 \mathrm{~kg}$ or below $30 \mathrm{~kg}$ or height in excess of $250 \mathrm{~cm}$ or below $100 \mathrm{~cm}$.
} 
respondents who are underweight is relatively small. We will see in our empirical analysis that this will lead to somewhat imprecise estimates for this area of the BMI distribution, especially for women. Our descriptive statistics do not show any considerable differences between overweight and normal weight women in terms of either hourly wage rate or employment prospects.

\section{Insert Figure 1 AND TABle 2 ABOUt here}

For overweight men, hourly wages are on average around 63 euro cents higher than for average weight men. 85 percent of men with a BMI higher than 25 are in employment, as opposed to 76 percent of men with a BMI smaller than 25. Moreoever, overweight and obese respondents on average rate their own health worse than normal weight respondents. Of course, such simple mean comparisons fail to take the effect of other observable variables into account. For instance, obesity is more prevalent in older workers, who also tend to be less healthy and have more lifetime work experience. Our regressions, both parametric and nonparametric, take this into account, yielding coefficients that have the familiar ceteris paribus interpretation.

Throughout our empirical analysis, we control for educational attainment, parental education, marital status, country of origin, the number of children in the household and their age, as well as work experience and its square. This is important as obesity has been shown to be associated with socio-economic factors that might also affect wages (Baum and Ruhm, 2009; Strulik, 2014). We also include dummies for different age categories, a respondent's region of residence, and the wave to which an observation pertains. Controls for whether a person works in a white- or blue-collar job, and has supervision duties or holds a higher management position are also included. ${ }^{4}$ All results are robust to including controls for self-reported health. We also created measures of personality traits such as openness, extraversion, neuroticism, agreeableness, reciprocity, self-esteem, and impulsivity. Most of these measures turned out to be neither jointly nor individually significant and were therefore not used for our analysis.

\footnotetext{
${ }^{4}$ We follow the International Standard Classification of Occupations (ISCO-88) definitions when determining whether a respondent works in a white-collar or blue-collar occupation. For example technical professionals are categorized as white-collar workers even if they work in manufacturing.
} 


\section{Methodology}

Our main tool of analysis is a generalized additive model (GAM) that allows for a semiparametric estimation of a regression model of the following form:

$$
Y_{i}=X_{i} \beta+f\left(B M I_{i}\right)+\epsilon_{i}
$$

where $Y_{i}$ is the log of hourly wages of person $i$ in our wage regression and an employment status dummy in our analysis of employment prospects. Our explanatory variable of interest, $B M I_{i}$, enters the model in a non-parametric fashion, whereas we assume a linear, parametric functional form for our control variables.

Intuitively, this method can be thought of as a smoothing technique that - unlike the common Kernel smoothers or moving average smoothers - allows us to control for the influence of covariates. GAMs have several advantages over parametric models such as OLS. Most importantly, they make for a more flexible functional form that allows us to accommodate effect patterns that cannot easily be observed by OLS, even if high-order polynomial terms are included. What is more, polynomial regression implicitly assumes that the relationship between the explanatory variable and the dependent variable is global, i.e. the same across all possible values of the independent variable. That may not always be true. Power transformations also have the disadvantage that the degree of the polynomial is usually arbitrarily picked by the researcher and small adjustments of the functional forms sometimes substantially alter results. In addition, measures of the model fit such as the $R^{2}$ statistic or the the Akaike Information Criterion (AIC) are often not suited to detect misspecifications of the functional form. Finally, the interpretation of higher-order parameters is not always straightforward, in particular if some coefficients turn out to be statistically significant while others are not. GAMs, on the other hand, are not subject to most of the above issues. They are more flexible in that they allow the relationship between the $\mathrm{Y}$ and $\mathrm{X}$ variable to vary across the range of $\mathrm{X}$. In other words, GAMs do not impose a global relationship but allow for local effects. The researcher also cannot arbitrarily pick a functional form. Instead, GAMs let the data pick the appropriate specification. Of course, using GAMs comes at a price. The method does not yield an easy to interpret, global point estimate. Instead interpretation is visual and thus less straightforward than a standard regression output. This is a likely reason explaining the lack of 
popularity of semi-parametric models. At the same time, the visual interpretation can be useful in identifying complex patterns that might be missed when interpreting standard regression output.

Estimation is based on the backfitting algorithm developed by Hastie and Tibshirani (1990) and explained in detail in Keele (2008). This approach involves an iterative process, based on partial residuals. We use $\hat{\beta}_{0}=\bar{Y}$ and $\hat{f}_{j}=X_{j}$ for all $j$, as starting values, which are collected in matrix $\mathbf{S}_{\mathbf{j}}$. In a first step, partial residuals are obtained for each variable using these starting values. For instance, ${\hat{e_{p}}}^{X_{1}}$ is obtained as ${\hat{e_{p}}}^{X_{1}}=Y_{j}-\sum_{j=2}^{k} S_{j}-\bar{Y}$. In a second step, each partial residual is regressed on the corresponding $X$-column. That is ${\hat{e_{p}}}^{X_{1}}$ is regressed on $X_{1},{\hat{e_{p}}}^{X_{2}}$ is regressed on $X_{2}$, etc.. The resulting coefficients are used to update matrix $\mathbf{S}_{\mathbf{j}}$, before the iteration starts over with step one. The procedure is repeated until the model converges in terms of infinitesimally small changes in the residual sum of squares. In a linear parametric setting the coefficients obtained using this iterative process will be the usual least squares estimates. In a semiparametric setting, the regression in step two is fitted using a smoother. More precisely, we use penalized cubic regression splines to smooth the estimated residuals on the BMI variable.

The smoothing parameter, which determines the number of knots, is chosen via generalized cross-validation (GCV). The idea behind cross-validation is to obtain so called cross-validation scores, for all potential values of the smoothing parameter commonly referred to as lambda (Hastie and Tibshirani, 1990). Each score is calculated as the average prediction error for a dataset that omits one observations at a time. In other words, the prediction error is calculated for all $n$ leave-one-out permutations then divided by $n$ and thus averaged into a cross-validation score. This is repeated for all possible values of lambda, and we then pick the lambda that is associated with the lowest score. Craven and Wahba (1978) suggest a computationally less intensive procedure that entails a degrees of freedom adjustment. This generalized cross-validation (GCV) score is:

$$
G C V_{s}=\frac{\sum_{i=1}^{n}\left[y_{i}-\hat{f}_{s}\left(x_{-i}\right)\right]^{2}}{(n-d f)^{2}} .
$$

It is important to note that unlike OLS with polynomials, this method is non-arbitrary in the sense that the researcher cannot manually pick any level of smoothness or any degree of polynomials. Loader (1999) points out that such automated smoothing, whereby the 
analysts do not have any control over the selection of the smoothing parameter, can lead to overfitting in some instances. Accordingly, he suggests adjusting the smoothing parameter using visual analysis. Sensitivity to these manual adjustments would indicate overfitting and susceptibility of the model to noise in the data. Fortunately for our study, manual adjustments turns out not to be necessary, i.e. overfitting is not an issue. To show this, we included a graph where we manually chose the bandwidth by rounding the bandwidth parameter yielded by GCV up to its closest integer, alongside the graph yielded by GCV (see Figures 2 and 3). The differences between regressions with automated (GCV) bandwith selection and manual - some might argue - arbitrary bandwidth selection are negligible. Neither approach yielded patterns with large spikes or other irregularities. If anything, the GCV algorithm leads to slightly more conservative estimates of the relationship between wages and BMI. For the employment models that have a binary dependent variable, the same backfitting algorithm can be used in the context of an iterated, reweighed least squares regression, as outlined in Wood (2006). All estimations were conducted using the MGCV package in R, which uses a Bayesian approach to calculate bias-adjusted variancecovariance matrices (Marra and Wood, 2012). These can be used for inferential procedures such us constructing confidence bands and conducting hypothesis tests. For both elements that enter parametrically and non-parametrically $p$-values can be calculated.

A methodological concern that is often mentioned in the context of our research question is variable endogeneity. Both potential reverse causality and omitted relevant variables might bias our estimates. For example, higher socio-economic status (SES) is likely to entail access to more nutritious food or more effective weight control measures. In the absence of controls for all SES-dimensions, we might overestimate the adverse effects of obesity on labor market outcomes. The most common strategy to deal with this problem is an instrumental variable (IV) regression. For example, a genetic predisposition (Norton and Han, 2008; Cawley, Han, and Norton, 2011) or the weight of family members (Brunello and D'Hombres, 2007, among others) are often used as instruments. Proponents of this strategy cite an adoption study by Grilo and Poguegeile (1991) that appears to show no correlation between a common household environment and household members' BMI. However, considering that family members share a common socio-economic environment, the validity of such an instrument is not beyond doubt. Given the focus of our paper on bias caused by a misspecification of the functional form and due to the lack of a potential 
instrument other than sibling BMI, we therefore deliberately refrain from applying the IV technique. What is more, our software package also does not have the capability of running IV in a semi-parametric setting. Moreover, respondents' body weight was also only surveyed in four consecutive waves of the SOEP. The resulting lack of variation in BMI over time obstructs the application of an individual fixed effects model. Consequently, the results of this paper should not be interpreted as fully causal effects.

\section{Empirical Results}

Our empirical analysis consists of the following steps. In order to render our work comparable to others, we first run an OLS regression of log hourly wages on BMI. However, we do not stop at this point. Instead, in a second step, we apply a semiparametric model to investigate whether the linear functional form masks important details about the relationship of interest. Third, we combine the semiparametric setup with stratification techniques in order to better isolate the channel through which bodyweight affects wages. Furthermore, we also subject our results to several robustness checks. Finally, we also apply a semiparametric model to gain a better understanding of the relationship between bodyweight and employment.

\subsection{Bodyweight and Wages - Parametric Model Results}

A regular, parametric OLS regression model of women's log-wages on the BMI variable indicates that a 1 point increase in BMI is associated with a decrease in wages of around 0.7 percent (see column (1) of Panel A in Table 3).

This effect is highly significant and robust to the inclusion of controls for health and a standard-set of socio-economic variables. In a specification in which BMI enters the regression equation both linearly and quadratically, neither coefficient is individually statistically significant. At first glance, all signs point to a linear relationship between BMI and hourly wages of about the same magnitude as has been found in other countries. ${ }^{5}$

\section{INSERT TABLE 3 ABOUT HERE}

\footnotetext{
${ }^{5}$ To the best of our knowledge, Cawley, Grabka, and Dean (2005) have conducted the only nationally representative study on the relationship between physical characteristics and earnings in Germany. However, they did not analyse the effect of body weight on hourly wages or employment.
} 
Our OLS-findings for men are also very much in line with previous studies, which usually arrive at the result that men are not subject to any weight penalties or premia in the labor market (Baum and Ford, 2004, among others). The BMI coefficient in our linear OLS specification is not statistically significant (see Panel B in Table 3), while the coefficients in our quadratic specification are barely statistically significant ( $p$-values $<0.1$ ).

\subsection{Bodyweight and Wages - Semiparametric Model Results}

It initially appears that, similar to the findings for other countries, women in Germany are subject to an obesity wage penalty, whereas men are not. However, our semiparametric model of the form of equation (1) shows that a linear functional form fails to uncover important details.

\section{INSERT TABLES 4 AND 5 ABOUT HERE}

First, note that the coefficients for the control variables are as expected (see Tables 4 and 5). For instance, college graduates earn higher wages, and log wages increase in age up to a point. Naturally, we cannot report any coefficients for our main explanatory variable, BMI, as it enters the model nonparametrically.

Therefore, it should be interpreted graphically, using Figure 2 for women and Figure 3 for men. Our model indicates that women's wages peak at a BMI of around 21.5, and steadily decrease for higher body weight. The point estimates indicate a wage penalty for underweight women, but due to the low number of observations the confidence bands are very wide in this region. As a result, we cannot rule out that underweight women earn hourly wages in the same order of magnitude as women in the lower normal-weight category. Either way, the early peak and subsequent drop in wages are not consistent with the notion of an obesity wage penalty due to health constraints. In fact, there appears to be no penalty for obesity, but rather a wage premium for slim women. The size of these effects is also not negligible. The wage gap between the peak and the region where the relationship starts to level out amounts to around 12 percent. ${ }^{6}$ This effect is unlikely to be driven by health effects, given that controls for self-reported health do not change our results. We cannot entirely rule out a compensating differentials story in which lower

\footnotetext{
${ }^{6}$ As mentioned above, these calculations are necessarily obtained by visual analysis. The peak is at $\log ($ wage $)=2.44$ while curve levels out at about 2.32 . This indicates a difference of about 1.30 Euros per hour which is $11.5 \%$ of the mean.
} 
wages reflect higher health insurance premia to be paid by the employer (Bhattacharya and Sood, 2011; Bhattacharya and Bundorf, 2009). However, there are two reasons to suspect that this is not the channel driving our results. First, Germany has essentially a singlepayer system in which employers are obliged to contribute to a employee's mandatory health plan. In particular they cannot opt out, although the size of the contribution is commensurate with the employee's earnings. Second, the downward trajectory of wages starts at a BMI-level that is not associated with adverse health outcomes. So while it is possible that health benefits play a role in driving this relationship, it seems more likely that physical appearance is the largest driving force behind our results, as female slimness is generally deemed as attractive (Stearns, 2002).

\section{INSERT Figure 2 ABOUt HERE}

For men, a regular OLS model also fails to uncover important details. Figure 3 provides evidence for wage penalties against men who are deemed too light. Wages then peak on a plateau that ranges from around $\mathrm{BMI}=23$ well into a $\mathrm{BMI}$ range in which individuals are considered overweight or even obese. At first glance, one might suspect that men are simply held to different beauty standards. Obesity is not punished in terms of lower wages, but rather underweight men are. In fact, even men in the lower bounds of the normal weight range are subject to wage penalties. Such a result is consistent with previous findings, and is commonly referred to as the "portly banker" effect (Cawley, 2004), i.e. the notion that higher weight might reflect power and authority. ${ }^{7}$ Consequently, underweight men might lack such an aura. This explains wage differences of 7-8 percent between underweight men and those with BMIs within the aforementioned plateau range.

\section{INSERT Figure 3 ABOUt HERE}

Moreoever, the likelihood ratio tests for the specifications for both men and women suggest that our semiparametric regressions differ significantly from parametric linear or quadratic setups (see $p$-values in bottom row of Table 3). Accordingly, it required the flexibel functional form of our semiparametric model to uncover the true, albeit not necessarily causal, relationship between hourly wages and bodyweight.

\footnotetext{
${ }^{7}$ Other studies, such as Greve (2008) and Lundborg, Nystedt, and Rooth (2014) also find such an underweight penalty, althouhg in the latter study it disappears once non-cognitive skills are controlled for.
} 


\subsection{Bodyweight and Wages - Stratification Results}

The previous section has already hinted that physical attractiveness is the main channel through which bodyweight affects female wages. We find further support for this hypothesis by stratifying our sample by occupational type. Looks tend to be more important in whitecollar occupations, within which employees interact with customers and coworkers more frequently. There is some evidence that good looks might be an asset in such circumstances (Hamermesh and Parker, 2005, among others). On the other hand, beauty is presumably less important in blue-collar occupations.

Our results suggest that the previously described pattern more or less holds for women in white-collar occupations (see bottom left of Figure 2), but not for women in blue-collar jobs. That is, wages for women in white-collar occupations peak at a BMI of about 22 and subsequently decrease in body weight. The semiparametric specification statistically significantly differs from both a linear and quadratic specification (see $p$-values for the LR-Test in the bottom row of Panel A in Table 3), which consequently fail to detect the same pattern.

For women in blue-collar jobs, the semiparametric results resemble the results of a linear regression model. In fact, our backfitting algorithm suggests a linear fit. Even if we force some non-linearity on the regression, the resulting line has little curvature (see bottom right of Figure 2). A likelihood ratio test also fails to reject the hypothesis that the parametric and semiparametric model come to the same result at any reasonable significance level. That is, higher bodyweight is strictly negatively associated with wages in blue-collar jobs. ${ }^{8}$

Stratification by occupational category also provides further insights regarding the apparent wage penalty against slender men. We find that there is essentially no effect of body weight on the wages of men in white-collar occupations. The semiparametric regression line in the bottom left graph in Figure 3 is somewhat bumpy, although the corresponding confidence intervals are sufficiently large to fit a horizontal line through them. A likelihood ratio test confirms that the semiparametric specification does not add much value compared to linear OLS ( $p$-value=0.079). However, body weight very much appears to be negatively associated with wages of men in blue-collar occupations (see

\footnotetext{
${ }^{8}$ The coefficients for the control variables are reported separately for women in white- and blue-collar jobs in columns (2) and (3) of Table 4.
} 
bottom right graph of Figure 3). In fact, the underweight penalty that we observe for the full sample appears to be mainly driven by blue-collar workers. Additional weight is associated with steep increases in the hourly wage rate within the normal weight range. Wages peak at a BMI of around 24, and subsequently level out. A likelihood ratio test indicates that the true pattern is better picked up by a semiparametric regression than a quadratic specification $(p$-value $=0.012)$, which predicts a wage peak at $\mathrm{BMI}=30.15$.

Put differently, body weight does not affect the wages of men in white-collar jobs, although it affects the wages of men in blue-collar occupations in the form of the aforementioned underweight penalty. In fact, even men at the lower bound of the normal weight category are subject to small wage penalties. This suggests that fitness and strength (and not different beauty standards) might be the driving forces behind this relationship. After all, such traits rarely matter in white-collar occupations. On the other hand, a higher BMI might well reflect more muscle mass, which tends to be productivity raising in blue-collar occupations. This story would be consistent with the results of Wada and Tekin (2010), who do not distinguish between blue- and white-collar jobs but have found that larger muscle mass is positively associated with male wages.

\subsection{Bodyweight and Wages - Robustness Checks}

Applying a semiparametric model and stratification techniques have provided us with a fresh look at the weight penalty. While our estimates should be interpreted as correlations rather than causally, our analysis suggests that bodyweight affects wages for women through good looks, which are generally associated with low bodyweight and are particularly valuable in white-collar occupations. Underweight and low weight men are subject to slimness penalties in blue-collar jobs, presumably because their stature does not provide them with the required strength in such occupations. We put these findings to three distinct robustness checks.

\subsubsection{Grip Strength}

In order to test our hypothesis of a fitness premium for men in blue-collar occupations, we include a measure of grip strength into our semiparametric regression model. Respondents in the SOEP were asked to squeeze a bar as hard as they could with one hand. The exercise was repeated for both hands and the maximum pressure exerted was recorded as 
a respondent's handgrip strength. This grip strength has been shown as a valid predictor not just of health and mortality risks in general, but also of overall muscular strength (Gale, Martyn, Cooper, and Sayer, 2007; Metter, Talbot, Schrager, and Conwit, 2002). When we include this measure into our semiparametric regression model for blue-collar workers, we find that BMI and wages are no longer correlated with each other. In particular, the underweight penalty disappears, which is what we would expect, given that a lower BMI should no longer reflect a lack of strength or fitness after controlling for muscle strength. However, the results of this specification should be interpreted with caution as grip strength per-se turns out not to be a significant predictor of wages. Moreover, the grip strength control was only available for a subsample $(\mathrm{n}=492)$ that might no longer be representative for the overall (blue-collar) population (see column (4) of Table 5). ${ }^{9}$

\subsubsection{Occupational Categories}

As a second robustness check, we explicitly classify jobs into occupations in which physical attractiveness might be productivity-enhancing, thus potentially explaining the wage premium for low BMI women. For this purpose, we use the Dictionary of Occupational Titles (DOT), which assigns each occupation a code that contains information on the typical relationship with other people in that job. A job can primarily involve either "mentoring" (e.g. a reverend), "negotiating" (e.g. a manager), "instructing" (e.g. a professor), "supervising" (e.g. a ship officer), "diverting" (e.g. a performing artist), "persuading" (e.g. a salesman), "serving" (e.g. a waiter), "speaking, signaling" (e.g. an engineer) or "taking instructions, helping" (e.g. a construction worker). ${ }^{10}$ All jobs that fall into a DOT category other than the last-mentioned are categorized as jobs whereby appearance might be productivity-enhancing. ${ }^{11}$ We run separate semiparametric regressions for employees in both job categories. The results are virtually identical to those from our white-collar / blue-collar stratification (see Figure 4). This is unsurprising given that looks are deemed productivity-enhancing in around 77 percent of white-collar jobs.

\footnotetext{
${ }^{9}$ We observe a statistically significant positive effect of the grip strength measure on the wages of women in blue-collar jobs. However, the sample size $(n=143)$ is too small to consider this conclusive evidence (see column (4) of Table 4). For both men and women in white-collar jobs, the result of the grip test is not found to be associated with wages.

${ }^{10}$ We follow Han, Norton, and Stearns (2009) in this approach. Baum and Ford (2004) and Pagan and Davila (1997) use similar classifications, the former study uses a measure of interpersonal customer interactions to distinguish differential effects across occupations.

${ }^{11}$ We also run a specification where occupations that mainly involve "speaking, signaling" were also excluded from this category, with the results being qualitatively the same.
} 


\subsubsection{Stratification by Age}

Youth and looks are clearly correlated. Hamermesh and Biddle (1994) show that old women are generally deemed physically attractive less frequently than their younger peers. Younger women might, therefore, be better able to leverage a socially desirable bodyweight to their advantage. In other words, if physical attractiveness is driving the results for women, we would expect the previously observed pattern to be driven primarily by younger women. We test this by roughly splitting our sample in half and separately evaluating the relationship between bodyweight and wages for women between 20 and 39 years of age, and women of 40 and 60 years of age. Figure 5 displays the results. For younger women, the familiar pattern emerges, and even becomes a little more pronounced. Wages peak at a BMI of around 22 and decline in increasing body weight. In fact, the negative effect of higher body weight does not appear to level off as quickly as in the pooled sample. This effect also broadly holds when we focus on members of this age group who work in white collar occupations. For women between 40 and 60, the result is different. Not surprisingly, this age group earns higher wages in general. More importantly, the earnings differential between women with a BMI of 22 and those with a BMI of 35 is much smaller in this age group. Put differently, the slimness premium is more pronounced for younger women, as one would expect if looks were the driving force. It is also noticeable that the relationship for the older age group is virtually linear; in fact a LR-test indicates little difference between the OLS and the GAM specification ( $p$-value $=0.107)$. The absence of a peak might also be caused by the small number of women with low BMI values. ${ }^{12}$ Of course, this analysis should be taken with a grain of salt since obesity among the younger population is a recent phenomenon and we might be confounding age- and cohort-effects. ${ }^{13}$

\subsection{Bodyweight and Employment: Parametric vs. Semiparametric Mod- els}

The semiparametric estimation technique of our GAM is also applied to the categorical outcome, which is employment. The dependent variable in this estimation is a dummy that adopts a value of 1 if a person is either self-employed or working for an employer, and

\footnotetext{
${ }^{12}$ Only 34 women were underweight for the 40 to 60 year old sample, less than half the number of underweight women between 20 and 39 years of age.

${ }^{13}$ The results are, largely consistent with (Lundborg, Bolin, Hoejgard, and Lindgren, 2006) who for their sample 50+ year old Europeans find that obese women earn about 10 percent less than their normal weight peers.
} 
zero otherwise. It should be noted that generalized linear models (GLMs) such as probit or logit models are still linear and parametric in their functional form. Only the application of the link function, such as the normal cumulative distribution in a probit model, induces some degree of non-linearity.

\section{Insert TABLE 6 ABOUt HERE}

Our results suggest that the linear functional form assumptions mask important relationships between the dependent variable and our main explanatory variable of interest. A regular probit model, whose marginal effects are provided by column (1) of Table 6 , would have suggested that the employment probability for women continuously declines with increased weight (see bottom graph of Figure 6). However, our GAM suggests that the pattern observed for wages also applies to employment probabilities to some degree. The probability of being in employment is highest for women with a BMI of around 23.5, and then decreases in additional body weight. Accordingly and similar to wages, employment propensity peaks way before the clinical threshold of obesity. A likelihood ratio test suggests that the non-parametric model significantly improves the fit ( $p$-value $<0.01)$ compared to probit models with linear or quadratic BMI parameters (see bottom row of Table 6 for the exact $p$-values). Note that it is best practice to use the untransformed scale (top panel in Figure 6) for visual analysis. Applying the link function can lead to distortions in the form of linearity (Keele, 2008). This also appears to be true in our case. When we transform our predictions into odds-ratios (see middle panel in Figure 6), the confidence intervals increase decisively, although pronounced differences remain between the GAM and the GLM results.

\section{INSERT Figure 6 ABOUt HERE}

For men, the differences between the GAM and a quadratic GLM specification are less obvious. The likelihood ratio test provides only weak evidence for an improvement in fit by a GAM ( $p$-value=0.052). Therefore, we conclude that the quadratic GLM model, whose coefficients are displayed in column (6) of Table 6, has the appropriate functional form. Very much like the GAM (see top graph in Figure 6), it suggests that bodyweight is positively associated with employment probabilities, albeit diminishingly so, with a peak is reached close to the obesity threshold. On the other hand, a regular GLM model, would 
have predicted employment prospects to steadily increase in body weight (see bottom graph of Figure 6 and coefficients in column (1) of Table 6).

It is noteworthy how much the results for employment resemble those for wages: both women's wages (in particular in white-collar jobs) and employment probabilities peak markedly before the obesity threshold, while both wages (in particular in blue-collar jobs) and employment probabilities are lower for men in the lower weight regions. This suggests that bodyweight affects employment and wages through the same channels, namely looks (for women) and strength (for men).

\section{Conlcusion and Discussion}

Our semiparametric regression model allows us to uncover wage and employment effects of bodyweight that are not easily observable through linear or dummy variable regressions. Many previous studies (Conley and Glauber, 2006; Atella, Pace, and Vuri, 2008, just to mention a few) on this issue have stressed the importance of an "obesity penalty" (Averett and Korenman, 1996) for women's labor market outcomes. On the other hand, our approach, shows these results in a different complexion; we find that a "slimness premium" exists, rather than an obesity penalty. This is more than a subtle difference for several reasons. First, health and health benefits (Bhattacharya and Bundorf, 2009) are unlikely to be the main reasons for an impact of bodyweight on wages, given that women's wages peak at BMI levels that cannot possibly reflect health constraints. Second, our findings indicate that women with BMIs that are most consistent with societal standards of physical attractiveness earn the highest wages. By combining semiparametric regression with stratification techniques, we manage to further qualify this finding. In particular, we uncover that the slimness premium is only prevalent in occupations where looks are likely to be productivity-enhancing such as white-collar jobs. While these findings support Hamermesh and Biddle (1994) in that beauty matters in the labor market, our results stand in contrast with their finding of across the board employer discrimination.

Of course, endogeneity remains an unresolved issue in both our study and generally in the literature on obesity and labor market outcomes. A randomized controlled trial (RCT) in the context of this research question is both unethical and impractical. In the absence of an RCT, creative field experiments such as a recent study by Rooth (2009) seem to offer the best hope in resolving this endogeneity issue. However, this approach runs into 
issues when it comes to the relationship between obesity and wages. It should be noted that our study is not based on exogeneous variation and hence our results should not be interpreted as causal effects. Our findings still provide some new insights. For example, they suggest that strength rather than looks is the driving force in the relationship between body weight and labor market success for men. Our flexible functional form reveals that the wage premium for overweight men found in some previous studies (Cawley, Grabka, and Dean, 2005, among others), masks what is really an "underweight penalty". Again, this is more than a subtle difference. For instance, Cawley (2004) and McLean and Moon (1980) were indicative of a "portly banker" effect, i.e. higher body weight reflecting power and authority, which consequently enhance wages in all occupations. By contrast, our study suggests that male body weight only matters in blue-collar occupations. In such jobs, a low body mass index tends to reflect a lack of muscular strength, causing lower wages.

We are among the first to apply a generalized additive model (GAM) to uncover nonlinear effects of body mass on employment prospects. While a regular, quadratic probit model appears to do a good job of capturing non-linearity for men, a semiparametric approach adds significant value in the employment regression for women. Here, we also find that female labor prospects peak at BMI values far below the levels that define overweight or even obesity. This finding casts further doubt on the notion of obesity's adverse effects on labor market outcomes via the health channel. As for men, the exact opposite is true, i.e. job prospects increase with body weight, albeit with decreasing returns, indicating that in this case bigger is indeed better.

There are some other, important lessons to be learned from our study. First, somewhat unconventional channels through which obesity can affect labor market outcomes should receive further attention, particular the role of muscle strength. If possible, innovative measures, such as the grip strength test should be used. To the best of our knowledge, Rooth (2011) and Lundborg, Nystedt, and Rooth (2014) are the only studies to have done so. Second, our analysis suggests that effect-heterogeneity greatly matters. After all, we find very distinct effects for men and women, as well as persons in white- and bluecollar jobs. Sample stratification techniques are therefore advisable. Finally, it is highly recommended to use flexible functional forms as provided by generalized additive models. Recent software implementations of the underlying algorithms into R and SAS should 
ease the use of these models. At the very least, researchers should allow for non-linearity using polynomials in a regular OLS-setting. Otherwise, they might fail to uncover complex relationships that are common in labor and health economics.

Future research should strive to better understand how exactly the wage premium for slim women operates. ${ }^{14}$ For instance, a dataset with more detailed information on a person's work place environment might help to single out occupations in which slimness might be particularly productivity-enhancing, as well as whether customer or coworker discrimination are more important. In the same vein, the effects of obesity on occupational sorting should receive more attention. Another, related avenue of future research pertains to employer provided incentives for healthier body weight as recently pioneered by Cawley and Price (2013).

\footnotetext{
${ }^{14}$ Dragone and Savorelli (2012) provide a theoretical model that could serve as a starting point.
} 


\section{References}

Allison, D., K. R. Fontaine, J. E. Manson, J. Stevens, and T. B. Vanitallie (1999): "Annual deaths attributable to obesity in the united states," Journal of the American Medical Association, 282(16), 1530-1538.

Atella, V., N. PACE, And D. Vuri (2008): "Are employers discriminating with respect to weight?," Economics \& Human Biology, 6(3), 305-329.

Averett, S., And S. Korenman (1996): "The Economic Reality of the Beauty Myth," The Journal of Human Resources, 31(2), 304-330.

BAum, C. L., AND W. F. Ford (2004): "The wage effects of obesity: a longitudinal study," Health Economics, 13(9), 885-899.

Baum, C. L., And C. J. Ruhm (2009): "Age, socioeconomic status and obesity growth," Journal of Health Economics, 28(3), 635-648.

Bhattacharya, J., And M. K. Bundorf (2009): "The incidence of the healthcare costs of obesity," Journal of Health Economics, 28(3), 649-658.

Bhattacharya, J., And N. Sood (2011): "Who Pays for Obesity?," Journal of Economic Perspectives, 25(1), 139-58.

Bound, J., C. Brown, and N. Mathiowetz (2001): "Measurement Error in Survey Data," in Handbook of Econometrics, ed. by J. Heckman, and E. Leamer, vol. 5, chap. 59, pp. 3705-3843. North-Holland Publishing, Oxford.

Brunello, G., And B. D'Hombres (2007): "Does body weight affect wages?" Economics \& Human Biology, 5(1), 1-19.

Burkhauser, R. V., And J. CAWley (2008): "Beyond BMI: The value of more accurate measures of fatness and obesity in social science research," Journal of Health Economics, $27(2), 519-529$.

Caliendo, M., and W.-S. Lee (2013): "Fat Chance! Obesity and the Transition from Unemployment to Employment," Economics and Human Biology, 11(2), 121-133.

CAWley, J. (2004): "The Impact of Obesity on Wages," The Journal of Human Resources, $34(2), 451-474$.

Cawley, J., and S. Danziger (2005): "Morbid obesity and the transition from welfare to work," Journal of Policy Analysis and Management, 24(4), 727-743.

Cawley, J., M. M. Grabka, and R. L. Dean (2005): "A Comparison of the Relationship Between Obesity and Earnings in the US and Germany," Schmollers Jahrbuch, 125, 119-129.

CaWley, J., E. Han, and E. C. Norton (2011): "The validity of genes related to neurotransmitters as instrumental variables," Health Economics, 20(8), 884-888.

Cawley, J., and J. C. Maclean (2012): "Unfit for Service: The Implications of Rising Obesity for Us Military Recruitment," Health Economics, 21(11), 1348-1366.

Cawley, J., and C. Meyerhoefer (2012): "The medical care costs of obesity: An instrumental variables approach," Journal of Health Economics, 31(1), 219-230.

CAWley, J., AND J. A. PRICE (2013): "A case study of a workplace wellness program that offers financial incentives for weight loss," Journal of Health Economics, 32(5), 794-803. 
Conley, D., and R. Glauber (2006): "Gender, Body Mass, and Socioeconomic Status: New Evidence from the PSID," in The Economics Of Obesity (Advances in Health Economics and Health Services Research), ed. by K. Bolin, and J. Cawley, vol. 17, pp. 253-275. Emerald Group Publishing Ltd.

Craven, P., and G. Wahba (1978): "Smoothing noisy data with spline functions," Numer. Math., 31(4), 377-403.

Dragone, D., and L. Savorelli (2012): "Thinness and obesity: A model of food consumption, health concerns, and social pressure," Journal of Health Economics, 31(1), $243-256$.

Gale, C. R., C. N. Martyn, C. Cooper, and A. A. Sayer (2007): "Grip Strength, Body Composition, and Mort," International Journal of Epidemiology, 36, 228-235.

Garcia, J., and C. Quintana-Domeque (2006): "Obesity, Employment and Wages in Europe," The Economics of Obesity, 17, 187-217.

Gregory, C. A., and C. J. Ruhm (2011): "Where Does the Labor Market Penalty Bite?," in Economic Aspects of Obesity, ed. by M. Grossman, and N. H. Mocan, chap. 11, pp. 315-347. Chicago University Press, Chicago.

Greve, J. (2008): "Obesity and labor market outcomes in Denmark," Economics \& $H u$ man Biology, 6(3), 350-362.

Grilo, C. M., And M. F. Poguegeile (1991): "The Nature of Environmental Influences on Weight and Obesity - A Behavior Genetic Analysis," Psychological Bulletin, 110(3), 520-537, Times Cited: 118.

Hamermesh, D. S., And J. E. Biddle (1994): "Beauty and the Labor Market," The American Economic Review, 84(5), 1174-1194.

Hamermesh, D. S., and A. Parker (2005): "Beauty in the Classroom: Instructors' Pulchritude and Putative Pedagogical Productivity," Economics of Education Review, 24(4), 369-376.

Han, E., E. C. Norton, and S. C. Stearns (2009): "Weight and wages: fat versus lean paychecks," Health Economics, 18(5), 535-548.

Hastie, T., and R. Tibshirani (1990): Generalized Additive Models: T. J. Hastie and R.J. Tibshirani. Chapman \& Hall.

Hildebrand, V., and P. Van Kerm (2010): "Body Size and Wages in Europe A SemiParametric Analysis," Ceps working paper, CEPS, Luxembourg.

Johansson, E., P. Backerman, U. Kitskinen, and M. Helivaara (2009): "Obesity and labour market success in Finland: The difference between having a high BMI and being fat," Economics \& Human Biology, 7(1), 36-45.

Keele, L. (2008): Semiparametric Regression for the Social Sciences. Wiley.

Kroh, M. (2011): "Documentation of Sample Sizes and Panel Attrition in the German Socio Economic Panel (SOEP) (1984 until 2010)," .

Lindeboom, M., P. Lundborg, and B. VAn Der KlaAuw (2010): "Assessing the impact of obesity on labor market outcomes," Economics $\& 3$ Human Biology, 8(3), 309319.

LOADER, C. (1999): Local Regression and Likelihood. Springer.

Lundborg, P., K. Bolin, S. Hoejgard, and B. Lindgren (2006): "Obesity and Occupational Attainment among the 50+ of Europe," 17, 219-251. 
Lundborg, P., P. Nystedt, And D.-O. Rooth (2014): "Body size, skills, and income: evidence from 150,000 teenage siblings," Demography, 51(5), 1573-1596.

Marra, G., And S. N. Wood (2012): "Coverage properties of confidence intervals for generalized additive model components," Scandinavian Journal of Statistics, 39(1), 5374.

McLean, R. A., and M. Moon (1980): "Health, obesity, and earnings," American Journal of Public Health, 70(9), 1006-1009.

Metter, J. A., L. A. Talbot, M. Schrager, and R. Conwit (2002): "Skeletal Muscle Strength as a Predictor of All-Cause Mortality in Healthy Men," The journals of Gerontology. Series A, Biological Sciences and Medical Sciences, 57, B359-B365.

Mocan, N. H., and E. Tekin (2011): "Obesity, Self-Esteem and Wages," in Economic Aspects of Obesity, ed. by M. Grossman, and N. H. Mocan. University of Chicago Press, Chicago.

Mokdad, A., E. S. Ford, B. A. Bowman, W. H. Dietz, V. S. Bales, and J. S. MARKS (2003): "Prevalence of obesity, diabetes, and obesity-related health risk factors, 2001," Journal of the American Medical Association, 289(1), 76-79.

Mokdad, A., M. Serdula, W. Dietz, B. Bowman, J. S. Marks, and J. P. Koplan (1999): "The spread of the obesity epidemic in the united states, 1991-1998," JAMA, 282(16), 1519-1522.

MorRis, S. (2006): "Body mass index and occupational attainment," Journal of Health Economics, 25(2), 347-364.

Norton, E. C., And E. HAN (2008): "Genetic information, obesity, and labor market outcomes," Health Economics, 17(9), 1089-1104.

Pagan, J. A., And A. Davila (1997): "Obesity, Occupational Attainment, and Earnings," Social Science Quarterly, 78(3), 756-770.

Paraponaris, A., B. Saliba, and B. Ventelou (2005): "Obesity, weight status and employability: Empirical evidence from a French national survey," Economics 83 Human Biology, 3(2), 241-258.

Rooth, D.-O. (2009): "Obesity, attractiveness, and differential treatment in hiring a field experiment," Journal of human resources, 44(3), 710-735.

(2011): "Work Out or Out of Work - The Labor Market Return to Physical Fitness and Leisure Sport Activities," Labour Economics, 18(3), 399-409.

Stearns, P. (2002): Fat History: Bodies and Beauty in the Modern West. New York University Press.

Strauss, R. S. (1999): "Comparison of measured and self-reported weight and height in a cross-sectional sample of young adolescents.," International Journal of Obesity 85 Related Metabolic Disorders, 23(8).

Strulik, H. (2014): "A mass phenomenon: The social evolution of obesity," Journal of Health Economics, 33, 113-125.

TAO, H.-L. (2008): "Attractive Physical Appearance vs. Good Academic Characteristics: Which Generates More Earnings," Kyklos, 61(1), 114-133.

Wada, R., And E. Tekin (2010): "Body composition and wages," Economics $\&$ Human Biology, 8(2), 242-254. 
Wagner, G., J. R. Frick, And J. Schupp (2007): "The German Socio-Economic Panel Study (SOEP) - Scope, Evolution and Enhancements," Schmollers Jahrbuch, 127(1), 139-169.

WHO (2000): "Obesity: Preventing and Managing a Global Epidemic," Discussion paper.

Wood, S. (2006): Generalized Additive Models: An Introduction with R. Taylor \& Francis Group. 


\section{Tables and Figures}

Table 1: Sample Selection and Item Non-Response

\begin{tabular}{lcc}
\hline \hline \multicolumn{1}{c}{ Step } & \multicolumn{2}{c}{ Estimation Sample } \\
& Women & Men \\
\hline Full Sample & 14,918 & 14,829 \\
Sample Restriction & & \\
- Drop Younger 20, Older 60 & 13,014 & 12,868 \\
- Drop Persons with Disabilities & 12,547 & 12,358 \\
- Weight/Height Imputed or Missing & 10,510 & 10,028 \\
- Weight/Height Implausibel & 10,493 & 10,027 \\
- Missing Socio-Economic Controls & 10,022 & 9,621 \\
\hline \hline
\end{tabular}

Source: SOEP v26, own calculations. Sample contains most recent observation for all respondents participating in either the 2002, 2004, 2006, or 2008 wave. 
Table 2: Descriptive Statistics - Sample Means

\begin{tabular}{|c|c|c|c|c|c|c|}
\hline & \multicolumn{3}{|c|}{ Women } & \multicolumn{3}{|c|}{ Men } \\
\hline & Full Sample & $\mathrm{BMI}<25$ & $\mathrm{BMI} \geq 25$ & Full Sample & $\mathrm{BMI}<25$ & $\mathrm{BMI} \geq 25$ \\
\hline \multirow[t]{2}{*}{ BMI } & 24.58 & 21.73 & 29.28 & 26.23 & 22.85 & 28.61 \\
\hline & $(4.647)$ & $(1.943)$ & $(3.944)$ & $(3.940)$ & $(1.644)$ & $(3.291)$ \\
\hline \multirow[t]{2}{*}{ Weight in $\mathrm{kg}$} & 68.00 & 60.60 & 80.17 & 84.29 & 73.95 & 91.59 \\
\hline & $(13.11)$ & $(6.821)$ & $(11.85)$ & $(13.93)$ & $(7.668)$ & $(12.68)$ \\
\hline \multirow[t]{2}{*}{ Height in $\mathrm{cm}$} & 166.4 & 166.9 & 165.4 & 179.2 & 179.8 & 178.8 \\
\hline & $(6.270)$ & $(6.217)$ & $(6.250)$ & $(7.016)$ & $(6.981)$ & $(7.012)$ \\
\hline \multirow[t]{2}{*}{$\mathrm{BMI} \geq 30$} & 0.125 & & & 0.149 & & \\
\hline & $(0.330)$ & & & $(0.357)$ & & \\
\hline \multirow[t]{2}{*}{$25 \leq \mathrm{BMI}<30$} & 0.253 & & & 0.437 & & \\
\hline & $(0.435)$ & & & $(0.496)$ & & \\
\hline \multirow[t]{2}{*}{$20 \leq \mathrm{BMI}<25$} & 0.500 & & & 0.389 & & \\
\hline & $(0.500)$ & & & $(0.488)$ & & \\
\hline \multirow[t]{2}{*}{$\mathrm{BMI}<20$} & 0.122 & & & 0.0248 & & \\
\hline & $(0.328)$ & & & $(0.156)$ & & \\
\hline \multirow[t]{2}{*}{ Hourly Wage in Euros } & 11.29 & 11.47 & 11.00 & 14.22 & 13.83 & 14.46 \\
\hline & $(8.766)$ & $(8.717)$ & $(8.839)$ & $(12.50)$ & $(14.02)$ & $(11.47)$ \\
\hline \multirow[t]{2}{*}{ Employed } & 0.690 & 0.695 & 0.682 & 0.810 & 0.757 & 0.848 \\
\hline & $(0.463)$ & $(0.461)$ & $(0.466)$ & $(0.392)$ & $(0.429)$ & $(0.359)$ \\
\hline \multirow[t]{2}{*}{ Age } & 41.94 & 39.89 & 45.32 & 41.91 & 37.94 & 44.72 \\
\hline & $(11.70)$ & $(11.73)$ & $(10.83)$ & $(11.88)$ & $(12.28)$ & $(10.73)$ \\
\hline \multirow[t]{2}{*}{ Number of Kids Younger than 16} & 0.370 & 0.389 & 0.338 & 0.344 & 0.320 & 0.362 \\
\hline & $(0.483)$ & $(0.488)$ & $(0.473)$ & $(0.475)$ & $(0.466)$ & $(0.481)$ \\
\hline \multirow{2}{*}{ Number of Kids in Household } & 0.595 & 0.625 & 0.546 & 0.565 & 0.516 & 0.600 \\
\hline & $(0.909)$ & $(0.916)$ & $(0.895)$ & $(0.910)$ & $(0.884)$ & $(0.926)$ \\
\hline \multirow[t]{2}{*}{ Married } & 0.617 & 0.570 & 0.695 & 0.588 & 0.449 & 0.686 \\
\hline & $(0.486)$ & $(0.495)$ & $(0.461)$ & $(0.492)$ & $(0.497)$ & $(0.464)$ \\
\hline \multirow[t]{2}{*}{ German } & 0.922 & 0.929 & 0.909 & 0.923 & 0.932 & 0.917 \\
\hline & $(0.269)$ & $(0.256)$ & $(0.287)$ & $(0.266)$ & $(0.251)$ & $(0.276)$ \\
\hline \multirow[t]{2}{*}{ 3rd Tier School Degree } & 0.228 & 0.189 & 0.291 & 0.273 & 0.235 & 0.300 \\
\hline & $(0.419)$ & $(0.392)$ & $(0.454)$ & $(0.446)$ & $(0.424)$ & $(0.458)$ \\
\hline \multirow[t]{2}{*}{ 1st Tier School Degree } & 0.302 & 0.353 & 0.218 & 0.334 & 0.389 & 0.295 \\
\hline & $(0.459)$ & $(0.478)$ & $(0.413)$ & $(0.472)$ & $(0.488)$ & $(0.456)$ \\
\hline \multirow[t]{2}{*}{ College Degree } & 0.211 & 0.229 & 0.181 & 0.249 & 0.251 & 0.248 \\
\hline & $(0.408)$ & $(0.420)$ & $(0.385)$ & $(0.432)$ & $(0.433)$ & $(0.432)$ \\
\hline \multirow[t]{2}{*}{ Very Good Health } & 0.104 & 0.129 & 0.0618 & 0.116 & 0.164 & 0.0819 \\
\hline & $(0.305)$ & $(0.336)$ & $(0.241)$ & $(0.320)$ & $(0.371)$ & $(0.274)$ \\
\hline Good Health & 0.471 & 0.512 & 0.403 & 0.485 & 0.523 & 0.458 \\
\hline & $(0.499)$ & $(0.500)$ & $(0.491)$ & $(0.500)$ & $(0.500)$ & $(0.498)$ \\
\hline Satisfactory Health & 0.302 & 0.264 & 0.364 & 0.297 & 0.230 & 0.344 \\
\hline & $(0.459)$ & $(0.441)$ & $(0.481)$ & $(0.457)$ & $(0.421)$ & $(0.475)$ \\
\hline Poor Health & 0.123 & 0.0943 & 0.171 & 0.103 & 0.0826 & 0.117 \\
\hline & $(0.329)$ & $(0.292)$ & $(0.376)$ & $(0.303)$ & $(0.275)$ & $(0.321)$ \\
\hline Experience & 9.138 & 8.058 & 10.92 & 10.11 & 7.929 & 11.65 \\
\hline & $(9.098)$ & $(8.539)$ & $(9.693)$ & $(10.66)$ & $(9.596)$ & $(11.10)$ \\
\hline White Collar & 0.454 & 0.473 & 0.422 & 0.340 & 0.330 & 0.347 \\
\hline & $(0.498)$ & $(0.499)$ & $(0.494)$ & $(0.474)$ & $(0.470)$ & $(0.476)$ \\
\hline Higher Management & 0.0750 & 0.0824 & 0.0629 & 0.180 & 0.177 & 0.182 \\
\hline & $(0.263)$ & $(0.275)$ & $(0.243)$ & $(0.384)$ & $(0.382)$ & $(0.386)$ \\
\hline Number of Observations & 10,022 & 6,235 & 3,787 & 9,621 & 3,983 & 5,638 \\
\hline
\end{tabular}

Notes: Standard deviations in parentheses. We also have information on the state in which each respondent lives as well as the survey year each respondent was interviewed in. Data Source: SOEP 2008, 2006, 2004, and 2002; version 26, SOEP, 2010, doi:10.5684/soep.v26. 
Table 3: OLS Regression Results: BMI and (Log) Wages

\begin{tabular}{|c|c|c|c|c|c|c|}
\hline \multicolumn{7}{|l|}{ Panel A: Women } \\
\hline & (1) & $(2)$ & $(3)$ & $(4)$ & $(5)$ & $(6)$ \\
\hline & \multicolumn{2}{|c|}{ Full Sample } & \multicolumn{2}{|c|}{ White-Collar } & \multicolumn{2}{|c|}{ Blue-Collar } \\
\hline BMI & $\begin{array}{c}-0.007^{* * *} \\
(0.001)\end{array}$ & $\begin{array}{c}0.002 \\
(0.011)\end{array}$ & $\begin{array}{c}-0.006^{* * *} \\
(0.002)\end{array}$ & $\begin{array}{c}0.008 \\
(0.012)\end{array}$ & $\begin{array}{c}-0.007^{* *} \\
(0.003)\end{array}$ & $\begin{array}{c}-0.025 \\
(0.025)\end{array}$ \\
\hline BMI Squared & & $\begin{array}{l}-0.000 \\
(0.000)\end{array}$ & & $\begin{array}{l}-0.0003 \\
(0.0002)\end{array}$ & & $\begin{array}{c}0.0003 \\
(0.0004)\end{array}$ \\
\hline Observations & 4,117 & 4,117 & 3,386 & 3,386 & 731 & 731 \\
\hline R-squared & 0.312 & 0.312 & 0.280 & 0.280 & 0.239 & 0.240 \\
\hline Controls Higher Management & No & No & Yes & Yes & $\mathrm{N} / \mathrm{A}$ & $\mathrm{N} / \mathrm{A}$ \\
\hline$p$-Value LR Test & 0.025 & 0.001 & 0.019 & 0.013 & 0.470 & 0.470 \\
\hline \multicolumn{7}{|l|}{ Panel B: Men } \\
\hline & (1) & $(2)$ & $(3)$ & (4) & $(5)$ & (6) \\
\hline & \multicolumn{2}{|c|}{ Full Sample } & \multicolumn{2}{|c|}{ White-Collar } & \multicolumn{2}{|c|}{ Blue-Collar } \\
\hline$\overline{\mathrm{BMI}}$ & $\begin{array}{l}-0.001 \\
(0.001)\end{array}$ & $\begin{array}{l}0.019 * \\
(0.010)\end{array}$ & $\begin{array}{c}-0.02 \\
(0.002)\end{array}$ & $\begin{array}{c}0.010 \\
(0.013)\end{array}$ & $\begin{array}{c}0.001 \\
(0.002)\end{array}$ & $\begin{array}{c}0.023^{*} \\
(0.014)\end{array}$ \\
\hline BMI Squared & & $\begin{array}{c}-0.0003^{*} \\
(0.000)\end{array}$ & & $\begin{array}{c}-0.000 \\
(0.0002)\end{array}$ & & $\begin{array}{l}-0.0003 \\
(0.0003)\end{array}$ \\
\hline Observations & 5,373 & 5,373 & 2,851 & 2,851 & 2,522 & 2,522 \\
\hline R-squared & 0.448 & 0.449 & 0.457 & 0.457 & 0.250 & 0.250 \\
\hline Controls Higher Management & No & No & Yes & Yes & $\mathrm{N} / \mathrm{A}$ & $\mathrm{N} / \mathrm{A}$ \\
\hline$p$-Value LR Test & 0.009 & 0.010 & 0.078 & 0.027 & 0.009 & 0.010 \\
\hline
\end{tabular}

Notes: Standard errors in parentheses

$* * * / * * / *$ indicate significance at the $1 \% / 5 \% / 10 \%$-level.

We also control for educational attainment, a set of age dummies, marital status, immigrant status, experience and its square, the number of children in the household and their age. Regional dummies are also included, so are dummies for the survey wave. 
Table 4: Semiparametric Regression Results for (Log) Wages - Women

\begin{tabular}{|c|c|c|c|c|}
\hline & $\begin{array}{c}(1) \\
\text { Baseline }\end{array}$ & $\begin{array}{c}(2) \\
\text { White Collar }\end{array}$ & $\begin{array}{c}(3) \\
\text { Blue Collar }\end{array}$ & $\begin{array}{c}(4) \\
\text { Grip Strength } \\
\text { (b) }\end{array}$ \\
\hline Number of Kids in Household & $\begin{array}{l}-0.018 \\
(0.031)\end{array}$ & $\begin{array}{l}-0.030 \\
(0.022)\end{array}$ & $\begin{array}{l}-0.031 \\
(0.041)\end{array}$ & $\begin{array}{l}-0.008 \\
(0.141)\end{array}$ \\
\hline Number of Kids Younger than 16 & $\begin{array}{l}-0.016 \\
(0.014)\end{array}$ & $\begin{array}{c}0.007 \\
(0.034)\end{array}$ & $\begin{array}{l}-0.088 \\
(0.066)\end{array}$ & $\begin{array}{l}-0.080 \\
(0.141)\end{array}$ \\
\hline Married & $\begin{array}{c}-0.041^{* *} \\
(0.018)\end{array}$ & $\begin{array}{c}-0.053^{* * *} \\
(0.019)\end{array}$ & $\begin{array}{c}0.052 \\
(0.042)\end{array}$ & $\begin{array}{c}0.057 \\
(0.126)\end{array}$ \\
\hline Separated & $\begin{array}{c}-0.072^{*} \\
(0.040)\end{array}$ & $\begin{array}{c}-0.122^{* *} \\
(0.044)\end{array}$ & $\begin{array}{c}0.175^{* *} \\
(0.082)\end{array}$ & $\begin{array}{c}0.195 \\
(0.256)\end{array}$ \\
\hline Divorced & $\begin{array}{l}-0.032 \\
(0.024)\end{array}$ & $\begin{array}{l}-0.043 \\
(0.026)\end{array}$ & $\begin{array}{c}0.052 \\
(0.055)\end{array}$ & $\begin{array}{c}0.032 \\
(0.161)\end{array}$ \\
\hline German & $\begin{array}{c}0.016 \\
(0.029)\end{array}$ & $\begin{array}{c}0.038 \\
(0.036)\end{array}$ & $\begin{array}{l}-0.023 \\
(0.047)\end{array}$ & $\begin{array}{l}-0.030 \\
(0.105)\end{array}$ \\
\hline 3rd Tier School Degree ${ }^{(a)}$ & $\begin{array}{c}-0.097^{* * *} \\
(0.018)\end{array}$ & $\begin{array}{c}-0.106^{* * *} \\
(0.021)\end{array}$ & $\begin{array}{c}-0.074^{* *} \\
(0.036)\end{array}$ & $\begin{array}{l}-0.131 \\
(0.098)\end{array}$ \\
\hline 1st Tier School Degree $e^{a)}$ & $\begin{array}{c}0.124^{* * *} \\
(0.018)\end{array}$ & $\begin{array}{c}0.095^{* * *} \\
(0.018)\end{array}$ & $\begin{array}{c}0.014 \\
(0.071)\end{array}$ & $\begin{array}{l}-0.181 \\
(0.179)\end{array}$ \\
\hline Other School Degree $(\mathrm{a})$ & $\begin{array}{c}-0.082^{* * *} \\
(0.030)\end{array}$ & $\begin{array}{c}-0.093^{* *} \\
(0.038)\end{array}$ & $\begin{array}{l}-0.020 \\
(0.052)\end{array}$ & $\begin{array}{l}-0.040 \\
(0.128)\end{array}$ \\
\hline College Degree & $\begin{array}{c}0.204^{* * *} \\
(0.018)\end{array}$ & $\begin{array}{c}0.120^{* * *} \\
(0.020)\end{array}$ & $\begin{array}{c}0.058 \\
(0.077)\end{array}$ & $\begin{array}{c}0.118 \\
(0.145)\end{array}$ \\
\hline Other Tertiary Degree & $\begin{array}{l}-0.010 \\
(0.014)\end{array}$ & $\begin{array}{l}-0.002 \\
(0.015)\end{array}$ & $\begin{array}{c}0.011 \\
(0.038)\end{array}$ & $\begin{array}{l}-0.032 \\
(0.095)\end{array}$ \\
\hline Experience & $\begin{array}{c}-0.011^{* * *} \\
(0.002)\end{array}$ & $\begin{array}{c}-0.010 * * * \\
(0.003)\end{array}$ & $\begin{array}{l}-0.006 \\
(0.006)\end{array}$ & $\begin{array}{c}0.028 \\
(0.015)\end{array}$ \\
\hline Experience Squared & $\begin{array}{l}0.000^{*} \\
(0.000)\end{array}$ & $\begin{array}{c}0.000 * * \\
(0.000)\end{array}$ & $\begin{array}{c}-0.000^{* * *} \\
(0.000)\end{array}$ & $\begin{array}{l}-0.000 \\
(0.000)\end{array}$ \\
\hline White Collar Occupation & $\begin{array}{c}0.271^{* * *} \\
(0.018)\end{array}$ & & & \\
\hline Higher Management & & $\begin{array}{c}0.238^{* * *} \\
(0.020)\end{array}$ & & \\
\hline Grip Strength & & & & $\begin{array}{c}0.001 \\
(0.001)\end{array}$ \\
\hline$p$-Value $f(B M I)$ & 0.000 & 0.001 & 0.021 & 0.069 \\
\hline Regional Dummies & Yes & Yes & Yes & Yes \\
\hline Year Dummies & Yes & Yes & Yes & Yes \\
\hline Age Dummies & Yes & Yes & Yes & Yes \\
\hline Observations & 4,117 & 3,386 & 731 & 143 \\
\hline Adjusted R-squared & 0.302 & 0.268 & 0.170 & 0.106 \\
\hline$p$-Value LR Test & 0.025 & 0.013 & 0.470 & 0.481 \\
\hline
\end{tabular}

Notes: Standard errors in parentheses

$* * * / * * / *$ indicate significance at the $1 \% / 5 \% / 10 \%$-level.

(a) Reference Group are those with a highschool degree that does not directly qualify for university entrance ("Realschulabschluss")

(b) These are the results for blue-collar workers for whom the grip strength measure was available. 
Table 5: Semiparametric Regression Results for (Log) Wages - Men

\begin{tabular}{|c|c|c|c|c|}
\hline & $\begin{array}{c}(1) \\
\text { Baseline }\end{array}$ & $\begin{array}{c}(2) \\
\text { White Collar }\end{array}$ & $\begin{array}{c}(3) \\
\text { Blue Collar }\end{array}$ & $\begin{array}{c}(4) \\
\text { Grip Strength } \\
\text { (b) }\end{array}$ \\
\hline Number of Kids in Household & $\begin{array}{c}0.026^{* *} \\
(0.011)\end{array}$ & $\begin{array}{c}0.031^{* *} \\
(0.015)\end{array}$ & $\begin{array}{c}0.009 \\
(0.014)\end{array}$ & $\begin{array}{c}0.016 \\
(0.035)\end{array}$ \\
\hline Number of Kids Younger than 16 & $\begin{array}{c}0.013 \\
(0.021)\end{array}$ & $\begin{array}{l}-0.001 \\
(0.030)\end{array}$ & $\begin{array}{l}-0.007 \\
(0.028)\end{array}$ & $\begin{array}{c}0.017 \\
(0.069)\end{array}$ \\
\hline Married & $\begin{array}{c}0.085^{* * *} \\
(0.016)\end{array}$ & $\begin{array}{c}0.077^{* * *} \\
(0.023)\end{array}$ & $\begin{array}{c}0.078^{* * *} \\
(0.022)\end{array}$ & $\begin{array}{c}0.077 \\
(0.053)\end{array}$ \\
\hline Separated & $\begin{array}{c}0.043 \\
(0.038)\end{array}$ & $\begin{array}{c}0.047 \\
(0.049)\end{array}$ & $\begin{array}{l}-0.056 \\
(0.055)\end{array}$ & $\begin{array}{l}-0.010 \\
(0.171)\end{array}$ \\
\hline Divorced & $\begin{array}{c}0.029 \\
(0.024)\end{array}$ & $\begin{array}{l}0.060^{*} \\
(0.034)\end{array}$ & $\begin{array}{c}0.008 \\
(0.031)\end{array}$ & $\begin{array}{l}0.019 \\
(0.074)\end{array}$ \\
\hline German & $\begin{array}{c}0.027 \\
(0.021)\end{array}$ & $\begin{array}{c}0.032 \\
(0.038)\end{array}$ & $\begin{array}{c}0.005 \\
(0.023)\end{array}$ & $\begin{array}{l}0.095^{*} \\
(0.055)\end{array}$ \\
\hline 3rd Tier School Degree ${ }^{(*)}$ & $\begin{array}{c}-0.063^{* * *} \\
(0.014)\end{array}$ & $\begin{array}{c}-0.074^{* * *} \\
(0.022)\end{array}$ & $\begin{array}{c}-0.041^{* *} \\
(0.017)\end{array}$ & $\begin{array}{l}-0.072 \\
(0.043)\end{array}$ \\
\hline 1st Tier School Degreee ${ }^{(a)}$ & $\begin{array}{c}0.077^{* * *} \\
(0.017)\end{array}$ & $\begin{array}{c}0.054^{* * *} \\
(0.020)\end{array}$ & $\begin{array}{l}-0.037 \\
(0.037)\end{array}$ & $\begin{array}{c}0.057 \\
(0.092)\end{array}$ \\
\hline Other School Degree ${ }^{(a)}$ & $\begin{array}{c}-0.156^{* * *} \\
(0.024)\end{array}$ & $\begin{array}{l}-0.091^{*} \\
(0.048)\end{array}$ & $\begin{array}{c}-0.108^{* * * *} \\
(0.027)\end{array}$ & $\begin{array}{l}-0.168^{*} \\
(0.066)\end{array}$ \\
\hline College Degree & $\begin{array}{c}0.252^{* * *} \\
(0.017)\end{array}$ & $\begin{array}{c}0.124^{* * *} \\
(0.021)\end{array}$ & $\begin{array}{l}-0.078^{*} \\
(0.046)\end{array}$ & $\begin{array}{c}0.004 \\
(0.108)\end{array}$ \\
\hline Other Tertiary Degree & $\begin{array}{l}0.024^{*} \\
(0.013)\end{array}$ & $\begin{array}{c}0.014 \\
(0.017)\end{array}$ & $\begin{array}{c}0.023 \\
(0.018)\end{array}$ & $\begin{array}{l}-0.007 \\
(0.047)\end{array}$ \\
\hline Experience & $\begin{array}{c}-0.012^{* * *} \\
(0.002)\end{array}$ & $\begin{array}{c}-0.008^{* * *} \\
(0.002)\end{array}$ & $\begin{array}{c}-0.016^{* * *} \\
(0.003)\end{array}$ & $\begin{array}{c}-0.019^{* * *} \\
(0.007)\end{array}$ \\
\hline Experience Squared & $\begin{array}{l}0.000^{* *} \\
(0.000)\end{array}$ & $\begin{array}{c}0.000 \\
(0.000)\end{array}$ & $\begin{array}{c}0.000^{* * *} \\
(0.000)\end{array}$ & $\begin{array}{c}0.000 \\
(0.000)\end{array}$ \\
\hline White Collar Occupation & $\begin{array}{c}0.197^{* * *} \\
(0.013)\end{array}$ & & & \\
\hline Higher Management & & $\begin{array}{c}0.283^{* * *} \\
(0.018)\end{array}$ & & \\
\hline Grip Strength & & & & $\begin{array}{c}0.000 \\
(0.000)\end{array}$ \\
\hline$p$-Value $f(B M I)$ & 0.078 & 0.365 & 0.084 & 0.670 \\
\hline Regional Dummies & Yes & Yes & Yes & Yes \\
\hline Year Dummies & Yes & Yes & Yes & Yes \\
\hline Age Dummies & Yes & Yes & Yes & Yes \\
\hline Observations & 5,373 & 2,851 & 2,522 & 489 \\
\hline Adjusted R-squared & 0.443 & 0.445 & 0.234 & 0.64 \\
\hline$p$-Value LR Rest & 0.006 & 0.078 & 0.010 & $\mathrm{n} / \mathrm{a}$ \\
\hline
\end{tabular}

Notes: Standard errors in parentheses

$* * * / * * / *$ indicate significance at the $1 \% / 5 \% / 10 \%$-level.

(a) Reference Group are those with a highschool degree that does not directly qualify for university entrance ("Realschulabschluss")

(b) These are the results for blue-collar workers for whom the grip strength measure was available. 
Table 6: Probit Model Results for Employment Probability (Marginal Effects at the Means)

\begin{tabular}{lcccccc}
\hline \hline & \multicolumn{3}{c}{ Women } & & Men & \\
\hline & $(1)$ & $(2)$ & $(3)^{(\mathrm{a})}$ & $(4)$ & $(5)$ & $(6)^{(\mathrm{a})}$ \\
BMI & $-0.005^{* * *}$ & $0.019^{* * *}$ & & 0.002 & $0.022^{* * *}$ & \\
& $(0.001)$ & $(0.007)$ & & $(0.005)$ & $(0.005)$ & \\
BMI Squared & & $-0.0004^{* * *}$ & & & $-0.0004^{* * *}$ & \\
& & $(0.0001)$ & & & $(0.0001)$ & \\
\hline Regional Dummies & Yes & Yes & Yes & Yes & Yes & Yes \\
Year Dummies & Yes & Yes & Yes & Yes & Yes & Yes \\
Observations & 10,022 & 10,022 & 10,022 & 9,621 & 9,621 & 9,621 \\
Psudeo R-Squared & 0.149 & 0.150 & 0.178 & 0.306 & 0.308 & 0.310 \\
Log Likelihood & -5279.38 & -5272.78 & -5269.00 & -3243.00 & -3232.17 & -3230.00 \\
$p$-Value LR-Test & 0.000 & 0.005 & $\mathrm{n} / \mathrm{a}$ & 0.000 & 0.072 & $\mathrm{n} / \mathrm{a}$ \\
\hline \hline
\end{tabular}

Notes: Standard errors in parentheses

$* * * / * * / *$ indicate significance at the $1 \% / 5 \% / 10 \%$-level.

We also control for educational attainment, a set of age dummies, marital status, immigrant status, experience and its square, the number of children in the household and their age. Regional dummies are also included, so are dummies for the survey wave.

(a) Semi-Parametric Model, i.e. BMI enters non-parametrically; in both instances the p-value for the BMI variable was $<0.001$. 
Figure 1: Distribution of BMI
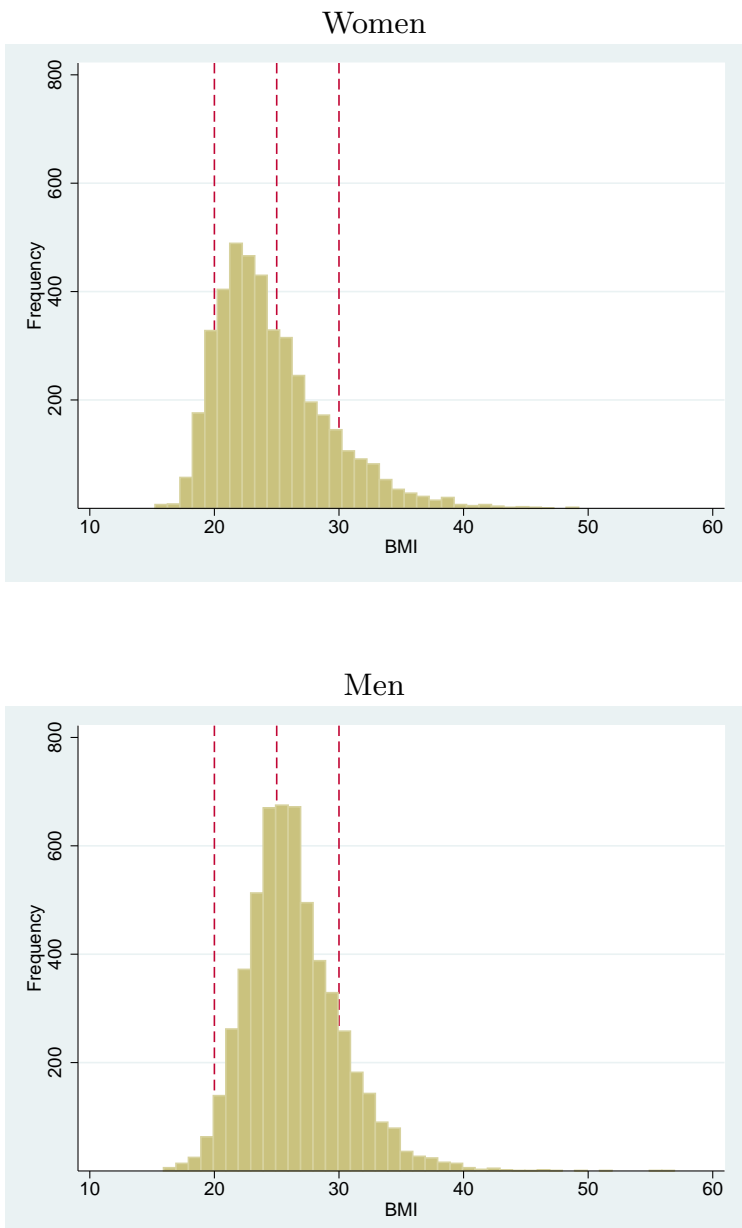

Notes: Graphs show the distribution of our main explanatory variable, Body Mass Index (BMI), for our wage sample, i.e. 20-60 year olds with valid wage data who work at least 20 hours per week. Rightmost vertical line indicates obestiy threshold, middle vertical line indicates overweight threshold, leftmost vertical line indicates normalweight threshold. 
Figure 2: BMI and Log Wages - Women
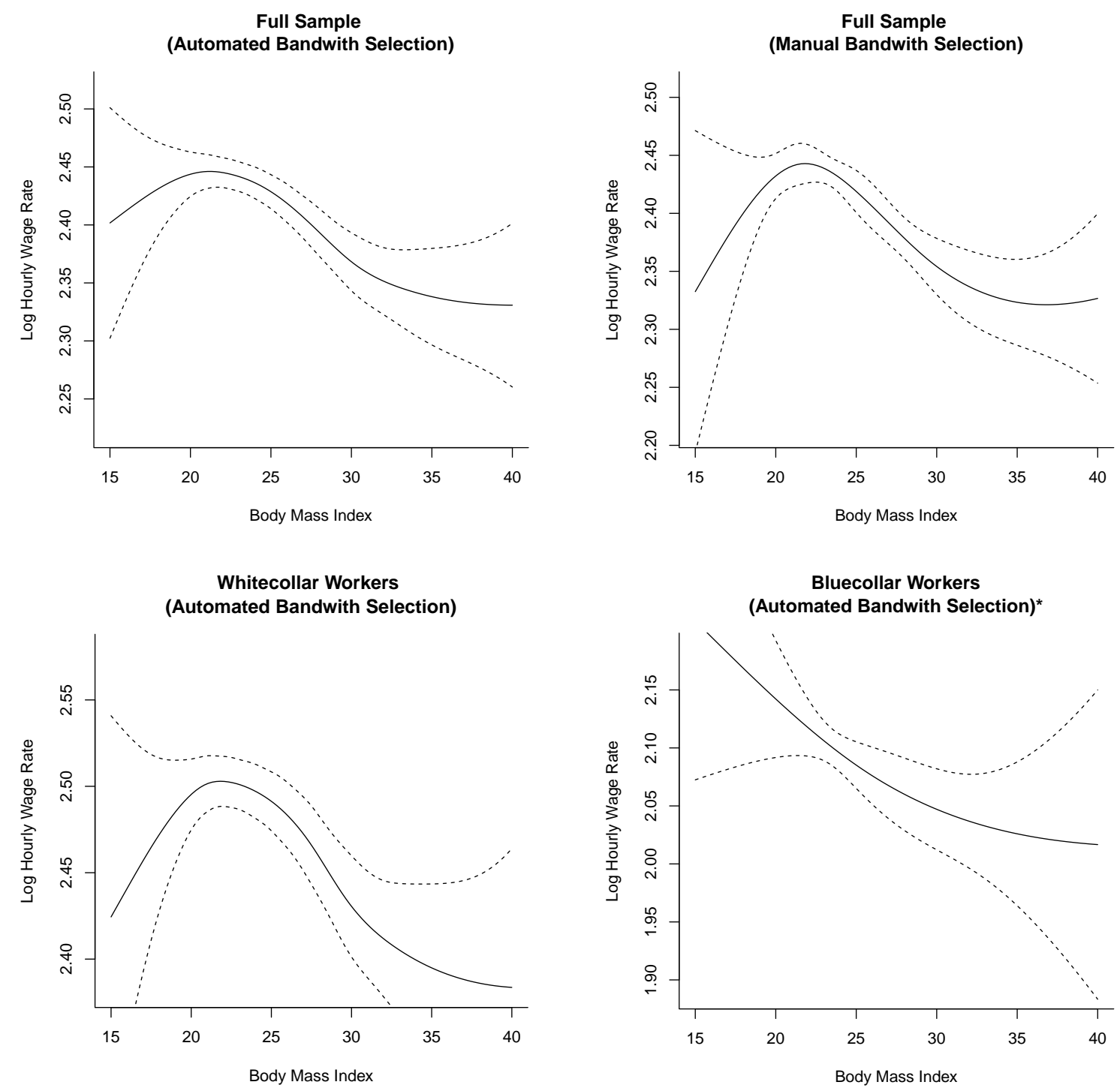

Notes: Graphs display the results of a semiparametric regression of log hourly wages on body mass index and a full set of control variables.

Solid line shows the effect of BMI on log hourly wages, and has the familiar ceteris paribus interpretation. Dashed lines are 95 percent confidence bands. Lines were shifted up by the average wage rate in the respective samples. Smoothing parameters were obtained using the automated cross-validation algorithm implemented in R's mgcv library.

* estimated with smallest possible bandwith, LR-test fails to reject null of linear effect. 
Figure 3: BMI and Log Wages - Men
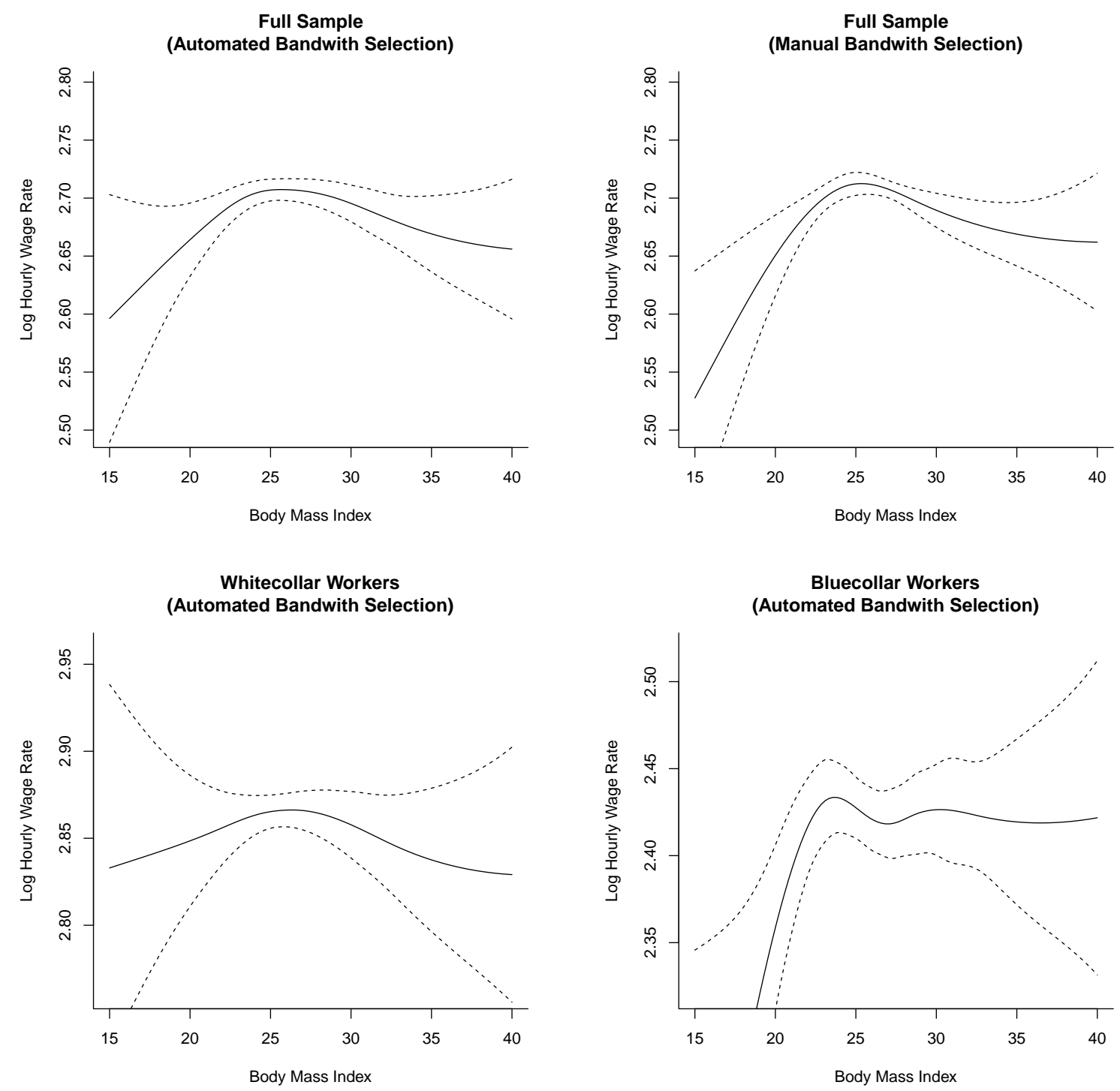

Notes: Graphs display the results of a semiparametric regression of log hourly wages on body mass index and a full set of control variables.

Solid line shows the effect of BMI on log hourly wages, and has the familiar ceteris paribus interpretation. Dashed lines are 95 percent confidence bands. Lines were shifted up by the average wage rate in the respective samples. Smoothing parameters were obtained using the automated cross-validation algorithm implemented in R's mgcv library. 
Figure 4: BMI and Log Wages by Occupational Category

Women

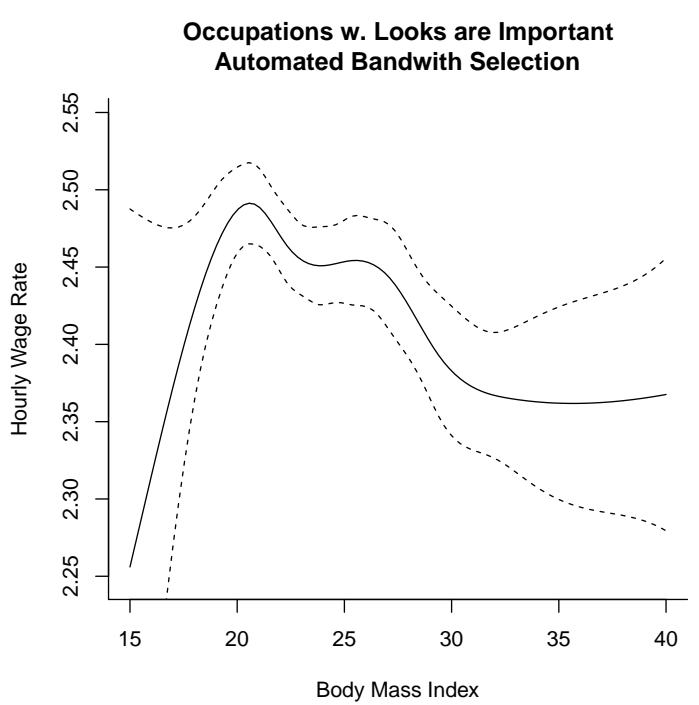

Looks Not Important in Job (Automaed Bandwith Selection)*

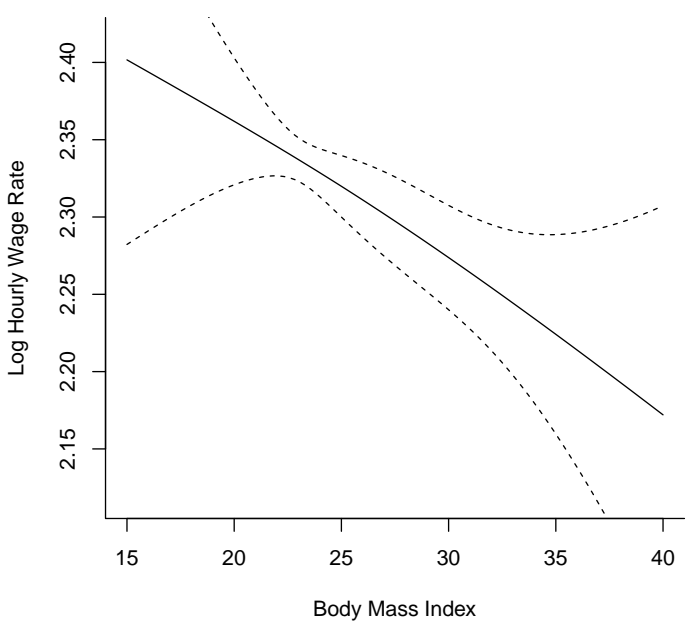

Men
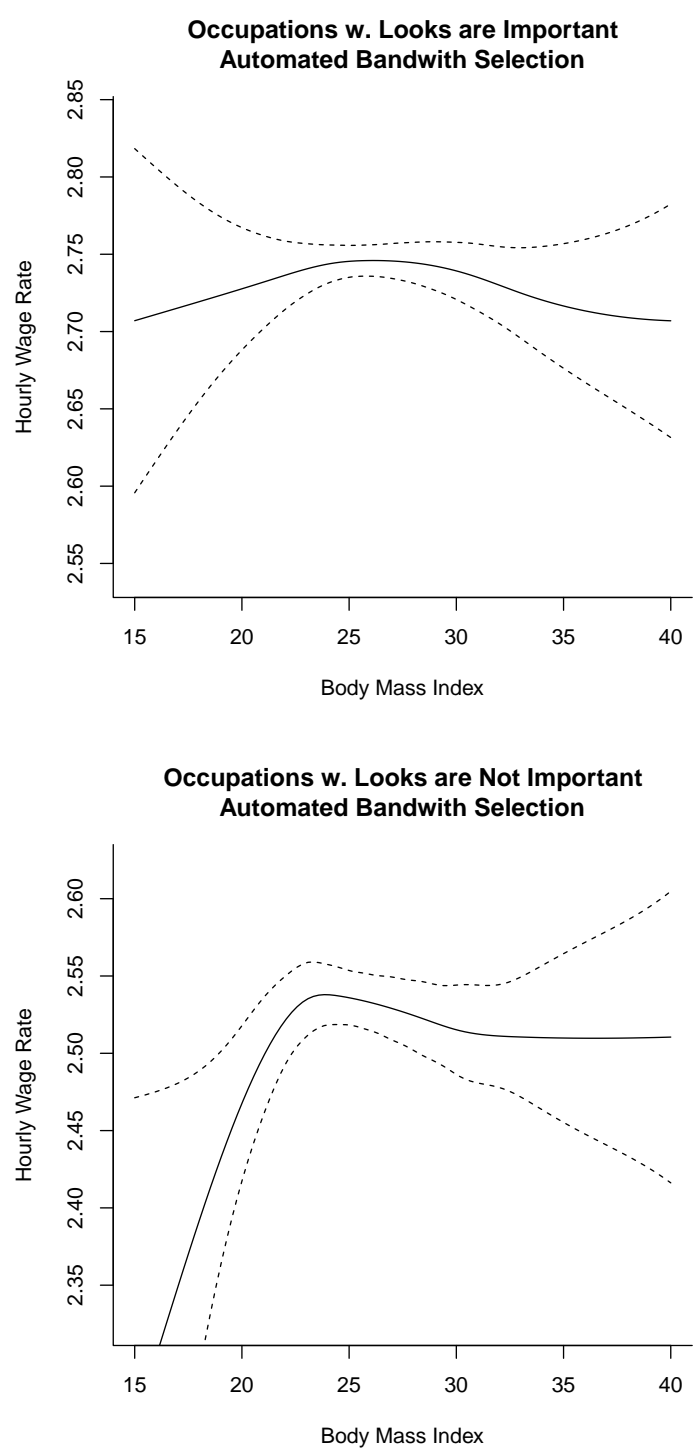

Notes: Graphs display the results of a semiparametric regression of log hourly wages on body mass index and a full set of control variables.

Solid line shows the effect of BMI on log hourly wages, and has the familiar ceteris paribus interpretation. Dashed lines are 95 percent confidence bands. Lines were shifted up by the average wage rate in the respective samples. Smoothing parameters were obtained using the automated cross-validation algorithm implemented in R's mgcv library.

* estimated with smallest possible bandwith, LR-test fails to reject null of linear effect. 
Figure 5: Stratification by Age - Women
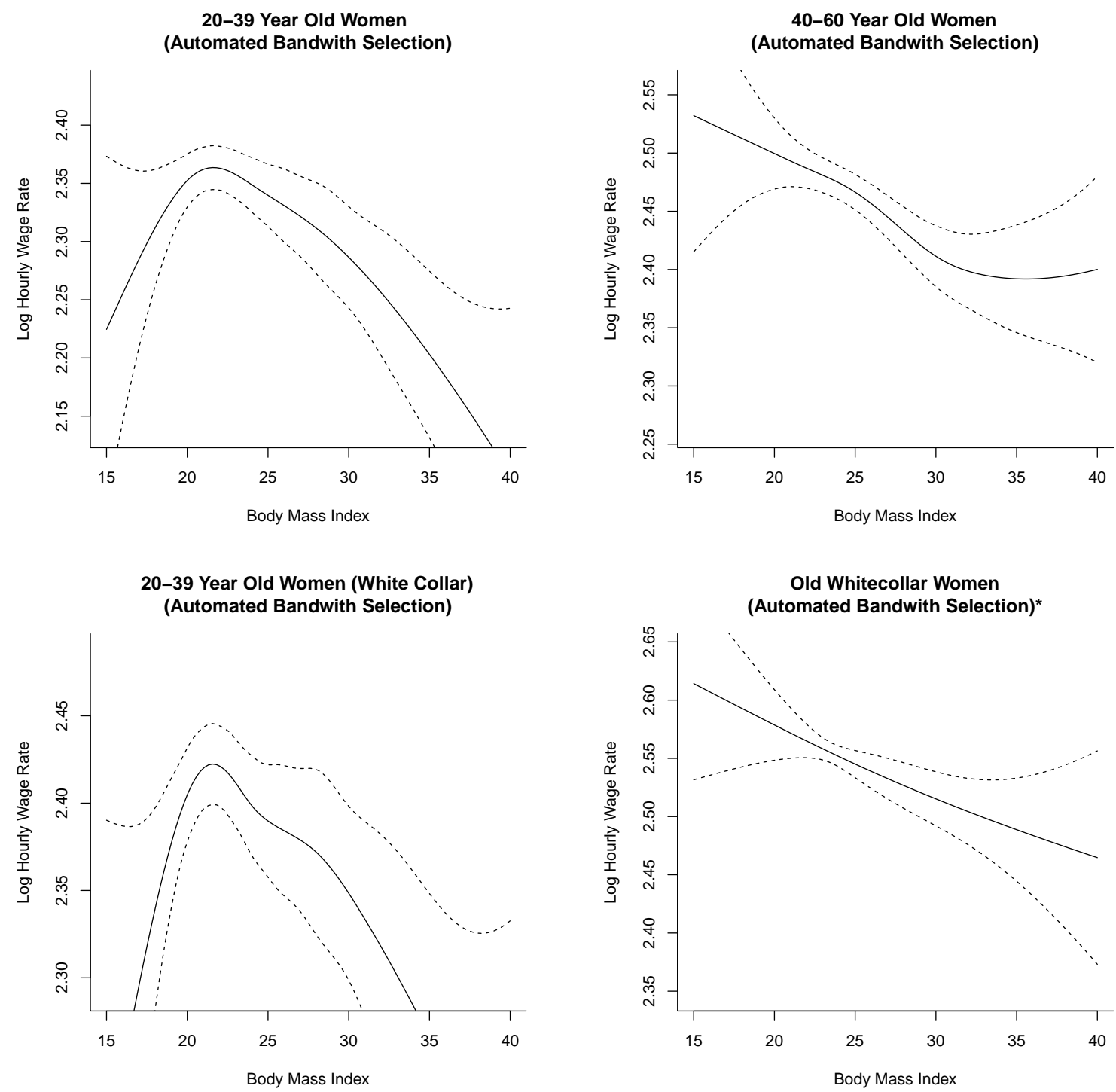

Notes: Graphs display the results of a semiparametric regression of log hourly wages on body mass index and a full set of control variables.

Solid line shows the effect of BMI on log hourly wages, and has the familiar ceteris paribus interpretation. Dashed lines are 95 percent confidence bands. Lines were shifted up by the average wage rate in the respective samples. Smoothing parameters were obtained using the automated cross-validation algorithm implemented in R's mgcv library.

* estimated with smallest possible bandwith, LR-test fails to reject null of linear effect. 
Figure 6: BMI and Employment

Women

GAM - Untransformed

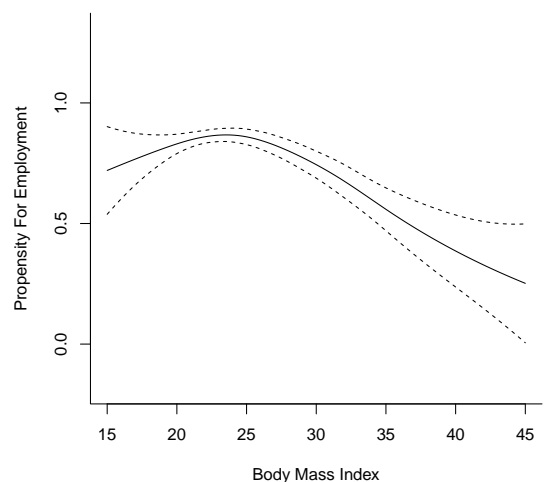

GAM - Odds Ratios

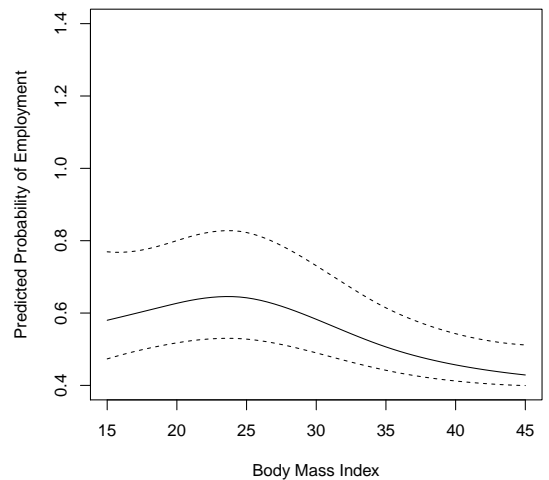

GLM - Odds Ratios

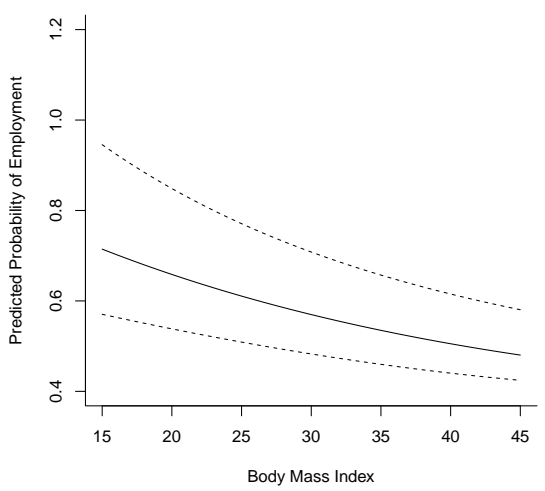

Men

GAM - Untransformed

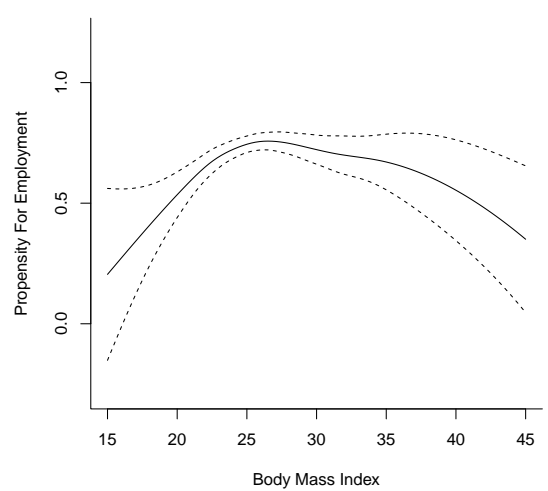

GAM - Odds Ratios

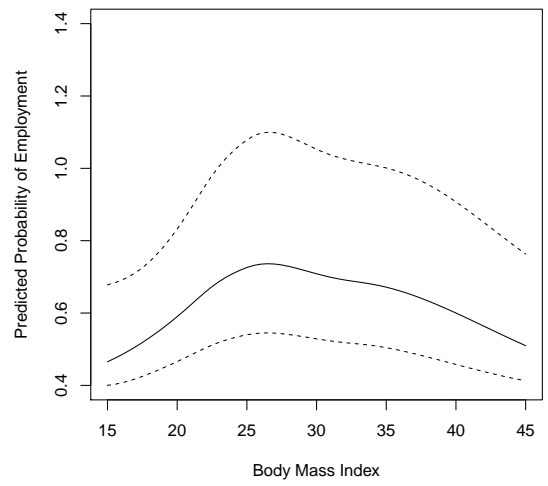

GLM - Odds Ratios

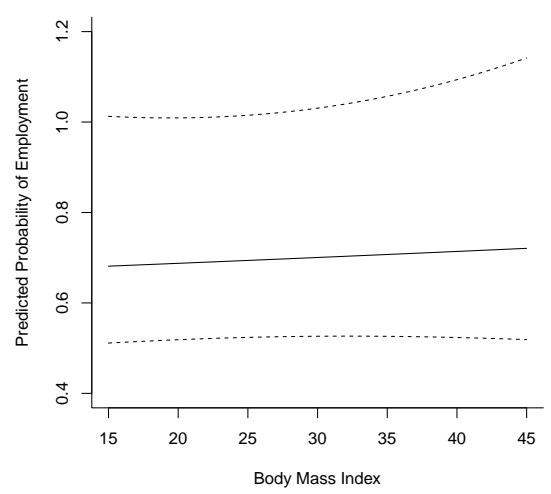

Notes: Graphs display the results of a semiparametric regression of an employment dummy on body mass index and a full set of control variables.

Solid line shows the effect of BMI on employment probabilities, and has the familiar ceteris paribus interpretation. Dashed lines are 95 percent confidence bands. Lines were shifted up by the average employment rate in the respective samples. Upper panels plot our nonparametric results in untransformed form, which is advisable for a diagnosis of non-linearity. Middle panels apply the probit link function and show the odd's ratios for our nonparametric model. Lower panels display the odd's ratios for a regular, parametric probit model. Smoothing parameters were obtained using the automated cross-validation algorithm implemented in R's mgcv library. 